\section{EMBRYAIDDLE Aeronautical University}

SCHOLARLY COMMONS

\section{International Journal of Aviation,} Aeronautics, and Aerospace

\title{
Manufacturing Process Simulation - On Its Way to Industrial Application
}

\author{
Dennis Otten \\ University of Applied Sciences Augsburg, rmit@otten-brothers.de \\ Tobias A. Weber \\ Airbus Helicopters Deutschland GmbH, webert1@my.erau.edu \\ Jan-Christoph Arent \\ Airbus Helicopters Deutschland GmbH, jan-christoph.arent@airbus.com
}

Follow this and additional works at: https://commons.erau.edu/ijaaa

Part of the Computer-Aided Engineering and Design Commons, Industrial Engineering Commons, Industrial Technology Commons, Manufacturing Commons, Structural Materials Commons, and the Structures and Materials Commons

\section{Scholarly Commons Citation}

Otten, D., Weber, T. A., \& Arent, J. (2018). Manufacturing Process Simulation - On Its Way to Industrial Application. International Journal of Aviation, Aeronautics, and Aerospace, 5(2). https://doi.org/10.15394/ ijaaa.2018.1217

This Article is brought to you for free and open access by the Journals at Scholarly Commons. It has been accepted for inclusion in International Journal of Aviation, Aeronautics, and Aerospace by an authorized administrator of Scholarly Commons. For more information, please contact commons@erau.edu. 


\section{Manufacturing Process Simulation - On Its Way to Industrial Application}

\section{Cover Page Footnote}

FOOTNOTE: Dennis Otten and Tobias A. Weber contributed equally to this work. ACKNOWLEDGEMENTS: Thanks go to the Bayerische Forschungsstiftung (BFS) for funding the project on sheet metal forming as part of the collaborative research center 'ForPro2 - Research alliance for efficient product and process development by knowledge based simulation'. Special thanks go to the BMW Group for providing parts and tooling geometries as well as material data. The development of the manufacturing process simulation for composite materials was self-funded by Airbus Helicopters Deutschland GmbH. 
Today manufacturing process simulation (MPS) becomes more and more important. Manufacturing with high performance metals and composite materials is expensive and requires sophisticated tooling and processes. An experienced based tooling and process design followed by a lengthy trial-and-error optimization process is just not contemporary anymore in today's competitive industrial environment (Duhovic, Schommer, Hausmann, Romanenko, \& Weber, 2017). Instead, a tooling design process aided by simulation is used more often. This is in direct correlation with the part design process which is supported by strength and stiffness evaluation simulations.

The shift of the optimization loop from a trial-and-error approach toward a simulation-based optimization within the virtual design phase not only reduces cost and time of tooling development but also increases the variety of feasible optimization options. (compare Figures 1a and 1b). Different manufacturing concepts can be evaluated and directly compared without the need for expensive and time consuming testing. This enables the tooling designer to select the most appropriate production method based on quantitative data rather than experience alone (Weber \& Balvers, 2015). As a result, the risk of selecting a concept that will not provide sufficient part quality is reduced.

Furthermore, the time for testing and industrialization of the selected manufacturing process will be reduced, because optimization can be done virtually long before the first tooling parts are produced. Changes to the tooling hardware after its manufacture are also reduced to a minimum due to the completely virtual process where only the computer aided engineering (CAE) models are altered rather than the hardware itself. Therefore, the substitution of the experimental trial-and-error optimization loop with a simulation reduces the tooling costs and thereby the nonrecurring costs (NRC) of the complete product development and production process. (Duhovic, Schommer, Hausmann, Romanenko, \& Weber, 2017).

In contrast, the original experience-based tooling design (Figure 1a) required the production of the molds and the first parts to discover short-comings in the chosen production set-up and the testing of possible optimizations. If problems with the part quality and/or the manufacturing process are discovered at this late stage (point $\mathrm{C}$ in Figure 1a) changes to tooling or manufacturing process are rather limited, since a tooling concept was already selected and expensive hardware produced. Furthermore, changes require a lot of manual rework on the tooling parts, which is rather expensive and time consuming. Therefore, shifting the optimization loop into the virtual tooling design phase (point A in Figure 1b) is definitely beneficial. 
a)

b)

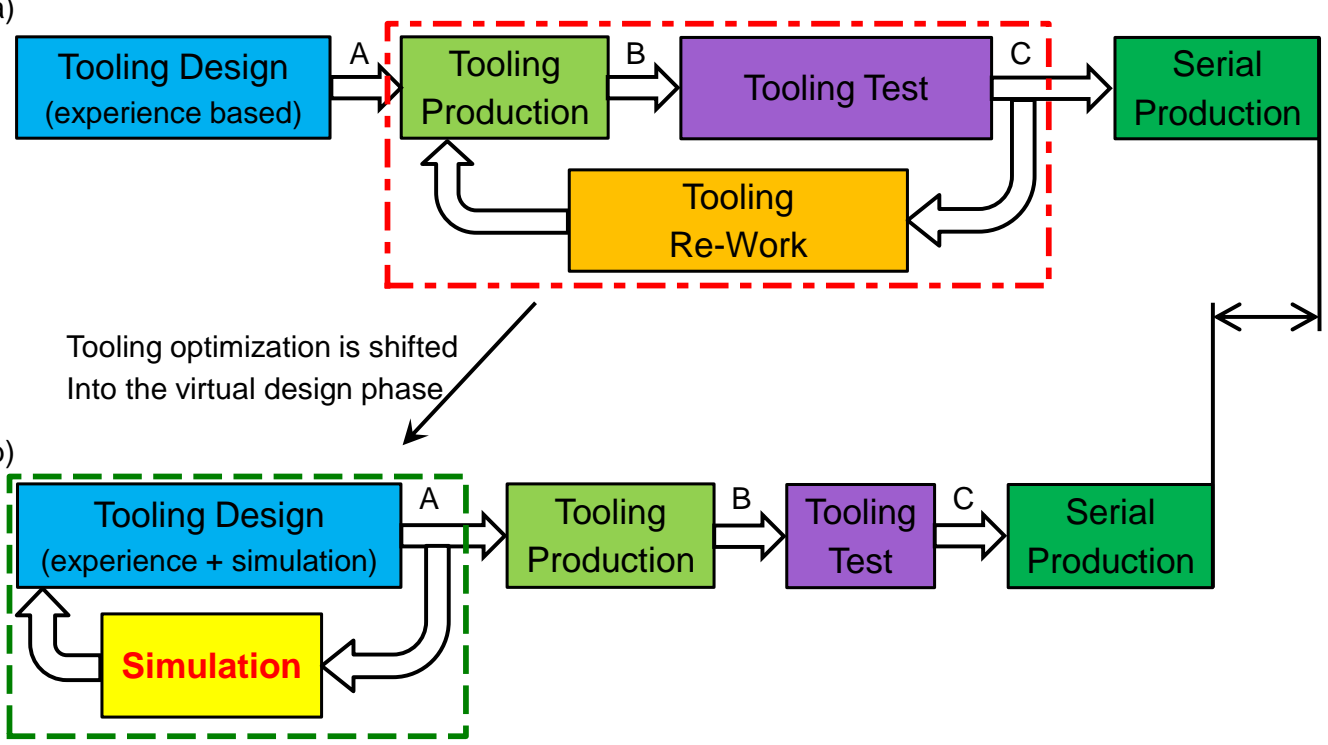

Figure 1. Tooling design process with (b) and without simulation (a)

Such a course of action, however, requires a sophisticated method for predicting the manufacturing outcome and the part quality before the first part is even produced. This is what MPS was developed for. Advanced material characterization and the evolution of finite element analysis (FEA) software tools provide the possibility to analyze the manufacturing process and predict the part quality within the early stages of the tooling development process (Duhovic et al., 2017). It so enables the tooling designer to analyze different tooling and manufacturing concepts and to select the one best suited for a given part.

MPS provides a lot of benefits for the tooling development but can do even more. It allows a much deeper look into the physics and phenomena behind a certain manufacturing process. Ideas for process or tooling optimization can be tested virtually and their feasibility as well as their profitability evaluated. Providing quantitative data for decision making is one of the major benefits of MPS.

This paper presents an overview of two sophisticated simulation techniques already being used in aeronautical (e.g. by Airbus Helicopters), aerospace (ESA's ARIANE 6) and automotive engineering (BMW's 7 Series) (Duhovic et al., 2017). One of these techniques is sheet metal forming simulation. The sheet metal forming process itself has been employed by the automotive industry for several decades now, but simulating its outcome in advance has not begun before the end of the $20^{\text {th }}$ century (Makinouchi, 1996). Metal forming and its simulation are also used in the aeronautical and aerospace industry. Structural aircraft and rocket parts, such as 
frames, stringers, and cleats are manufactured using metal forming (Raju, Ganesan, \& Karthikeyan, 2010).

Moreover, metal forming in the automotive industry is not just used for structural parts of the car frame but also for exterior blanks. External design parts require a perfect outer shape without wrinkles or scratches since they cannot always be concealed by paint (Kleiner, Geiger, \& Klaus, 2003; Jaina, Allina, \& Bullb, 1998; Ghouati \& Chen, 2006). The forming process must therefore avoid scratches that may occur due to friction between blank and tooling. Structural parts do not have equally high requirements concerning the surface quality. However, wrinkles in these parts cannot be tolerated either, because they might change the geometry and even the structural properties. For both problems forming simulations offer a solution. Although they are rather complex and often time consuming, they offer many significant advantages that will be summarized in this paper.

It is the authors' intention to show how simulation supports the tooling and process design as well as the industrialization process of the manufacturing concept and thus also the product maturation process. Furthermore, the validity of such simulations, their accuracy, and error approximation will be discussed.

The second MPS closely analyzed in this paper is the simulation of prepreg autoclave manufacturing of composite parts, a manufacturing technique that is well established in the aeronautical sector. Simulating composite manufacturing on an industrial scale began when Airbus, Boeing and Sikorsky decided to develop planes and helicopters consisting of more than 50\% composite materials like the Airbus A350XWB, the Airbus Helicopters H160, the Boeing B787 Dreamliner, and the Sikorsky CH-53K (Johnston, 1997; Brauner, 2013, Lukaszewicz, Ward \& Potter, 2011; Sikorsky, 2016; Osborne, 2015). The superior material properties including corrosion resistance, high specific strength, and fatigue resistance as well as the resulting weight reduction potential are the major reasons for this development (Younossi, Kennedy, \& Graser, 2001). The authors will provide an overview of a typical simulation process necessary to predict the manufacturing outcome for prepreg autoclave production. The basic physical phenomena covered in the simulation will be described briefly and automation methods for an industrial application provided.

Altogether, this paper provides an overview of the capabilities of MPS in the fields of sheet metal forming as well as prepreg autoclave manufacturing of composite parts summarizing the resulting benefits for tooling design and manufacturing engineering. Small case studies provide examples of an efficient application of the simulation on an industrial scale. 


\section{State-of-the-Art in Manufacturing Process Simulation}

\section{Metal Forming Simulation}

Metal forming is an irreversible change of the geometric shape of a thin metal sheet. To create irreversible deformations, the forming process takes place in the plastic regime of the stress-strain-relationship. It uses a punch and a die to stretch and press the metal sheet (so-called blank) into its new form (see Figure 2).

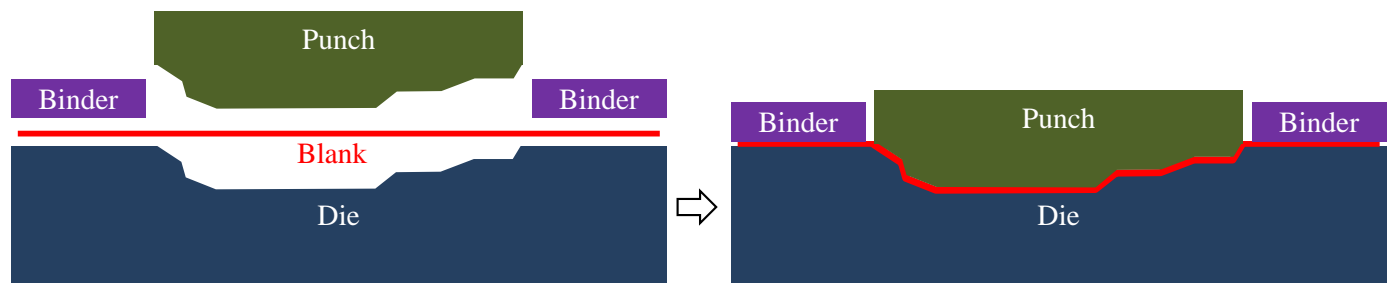

Figure 2. Sheet metal forming process

Although the process mainly takes place in the plastic regime of the stressstrain-relationship, the elastic regime is affected as well. This leads to spring-back while opening the mold and thereby partly releasing the elastic stress until a new energetically favorable equilibrium is reached by the formed part (Kobayashi et al 1989). By compensating the spring-back in the tooling design, the difference between as-designed and as-built can be minimized resulting in lower assembly costs (Najafi, Rais-Rohani, \& Hammi, 2001).

Without process simulation the compensation of punch and die is a time consuming and costly iterative process of producing parts, measuring their spring-back and changing the tooling geometry until a satisfactorily small difference between as-designed and as-built geometry is reached. This costly process can be minimized by applying an accurate spring-back simulation and performing the compensation action virtually through changing just the digital tooling model rather than the physical one.

It is obvious that designing a combination of punch and die cannot be achieved by simply deriving their surfaces from the desired part geometry. As explained in Figure 1 and the Introduction Section of this paper, tooling design can either be done using an experience-based design followed by experimental trialand-error optimization or by incorporating MPS (in this case sheet metal forming 
simulation) into the design process. MPS, however, requires the application of sophisticated finite element analysis (FEA) techniques starting by applying the correct material model.

An elastic-plastic material behavior has to contain three major aspects to be applicable for a forming simulation (Kobayashi, Oh, \& Altan, 1989). The stressstrain relationship must be described by a yield curve. A yield locus has to indicate at which combinations of stresses yielding occurs, and a hardening rule is required to predict the changes of the yield locus due to hardening.

Since forming takes place in a rather large displacement range, the stressstrain-relationship has to be presented as a true stress-strain curve as shown in Figure 3 right. The yield curve can be represented as a linear approximation from the initial yield value to a chosen maximum (black line from MAT_003 in Figure 3 right) or as a piecewise linear interpolation between two measured values (red dotted line in Figure 3 right) (Livermore Software Technology Corporation, 2012).

The yield locus is usually presented in a 2D principle stress representation (Figure 3 left). In the simplest case the yield locus is represented by an elliptical shape, when the von Mises yield criterion (relevant for mild steels) or the Tresca yield criterion (relevant for aluminum alloys) is applied. Sheet metal does, however, not act fully isotropically as the von Mises yield criterion assumes. Anisotropy values (R-values) larger than one characterizes typical transverse anisotropy. For those R-values the elliptical shape of the yield locus (von Mises criterion) changes to larger values in the first and third quadrant and to slightly smaller values in the second and fourth quadrant as shown by the rather simple anisotropic Hill '48 material model. More sophisticated models change the shape of the yield locus with multiple parameters to reflect measured behavior of the blank material (Banabic et al., 2008).

Two major kinds of hardening behavior can be applied to a forming simulation. The first is the isotropic hardening where the yield locus simply expands in all directions during hardening. The second is the kinematic hardening where the yield locus translates in the direction of the hardening. 

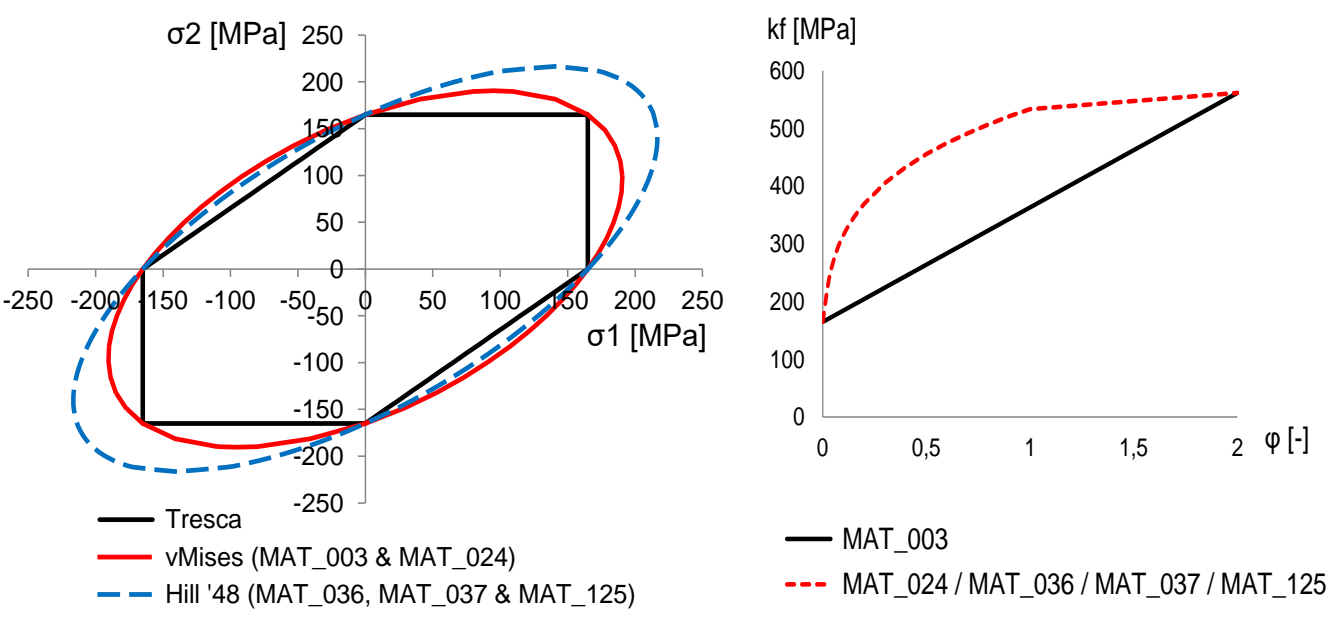

Figure 3. Yield locus(left) and yield curve (right) for some material models in FE (LS-DYNA)

There are two major applications for simulating metal forming processes. The first one is a feasibility study where the overall design of a part is tested. The modelling method of the blank is less complex than for a full-scale process simulation (Maker \& Zhu, 2000; Maker \& Zhu 2001). The main focus in this case is to decide whether the part is producible without major defects like cracks or wrinkles (Altan \& Tekkaya, 2012). The main drivers of this simulation are forces of the binder and, if applicable, of the draw beads which control the material flow of the blank (Cao \& Boyce, 1993). Moreover, the blank material might be changed to obtain a more robust design as far as avoiding major defects is concerned. The drawing result is evaluated by means of the forming limit diagram (FLD) in a rather simple way shown for a demonstrator part in Figure 4. This diagram presents the minor plastic strain vs. the major plastic strain. Multiple limits are defined indicating the risk of defects like thinning, cracks, or wrinkles (Strano \& Colosimob, 2006). 

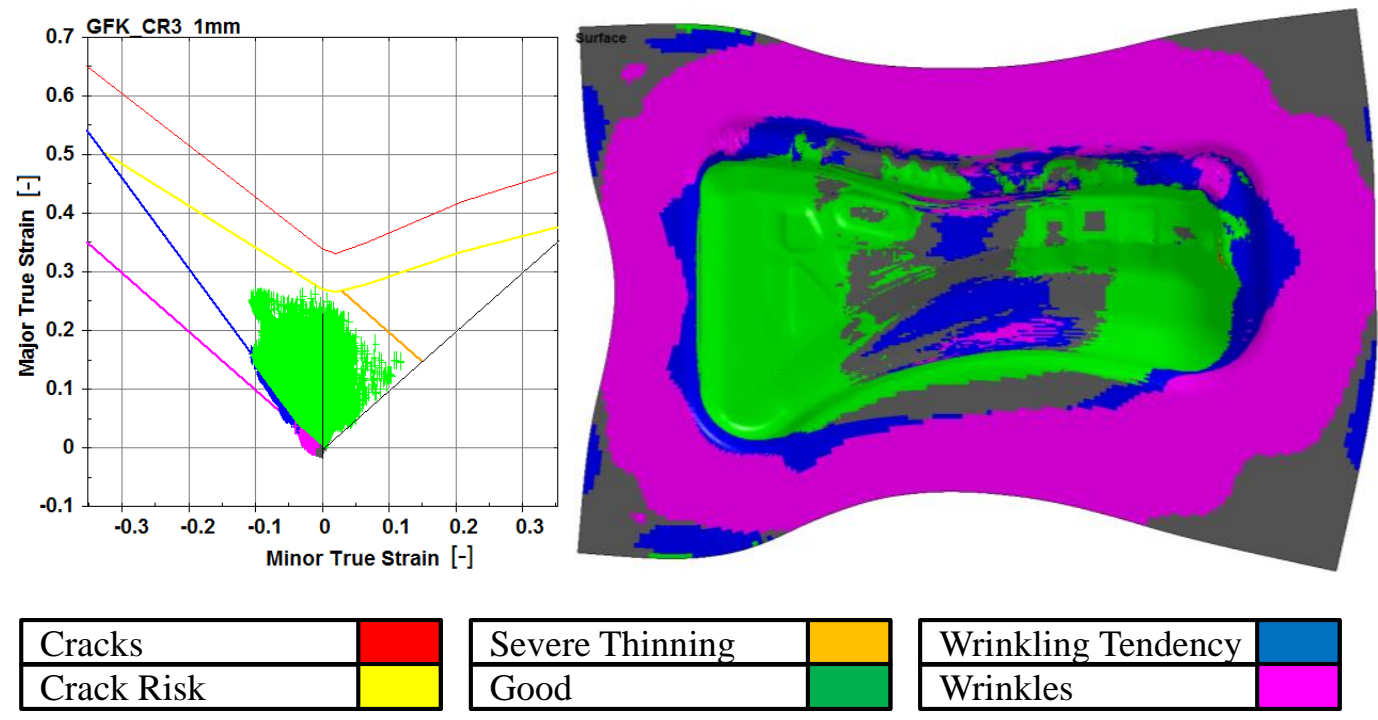

Figure 4. Forming limit diagram of demonstrator part at end of drawing process

For each element of the blank the combination of minor and major plastic strain is determined in the drawing process and can be displayed in the diagram. Commercial software tools, which can be used for the post-processing of the simulation results, are able to display the FLD results directly in the FLD diagram as well as on the mesh of the deformed blank for an easier evaluation of the entire part shown in Figure 4.

In addition to a simple feasibility study a more complex robustness or sensitivity analysis can be performed by changing multiple parameters in a reasonable range, either in a full factorial experimental design or by other means of experimental design. Typical parameters for this study are material properties like the young's modulus or anisotropy and geometric values such as sheet thickness and positioning of the blank in the tool (Atzema, Abspoel, Kömmelt, \& Lambriks, 2009). Beside the detection of flaws (wrinkles or cracks) the simulation results are suitable for evaluating the thickness distribution and necessary process forces for the punch, binder, and, if applicable, draw beads (Tekkaya, 2000).

The second major application of the forming simulation is a full-scale springback simulation. It is performed in multiple steps and usually uses a refined modelling method for the blank. In a first step the forming simulation is performed similar to the feasibility study with an explicit time integration method like the central difference method. However, a more complex element formulation leads to a more accurate forming result with the drawback of a much more time-consuming calculation. In addition to the more complex integration scheme, a larger number 
of integration planes in thickness direction is employed (Maker \& Zhu, 2000; Maker \& Zhu, 2001). In the second step the actual spring-back simulation is performed with an implicit time integration method to avoid oscillations (Maker \& Zhu, 2001). The simulation enables the user to evaluate the spring-back geometry and additionally more accurate process forces and thickness distributions. While the accuracy of the drawing simulation is considered to be relatively high, the accuracy of the spring-back prediction is driven by the yield locus and Young's modulus and remains a major field of research (Yao, Liu, Du \& Hu, 2002).

\section{Composite Materials Simulation}

The most common composite manufacturing method in the aviation industry is the autoclave thermoset pre-impregnated (prepreg) manufacturing (Elkington, Bloom, Ward, Chatzimichali, \& Potter, 2015; Weber, Arent, Steffens, Balvers, Duhovic, 2016; Weber \& Balvers, 2015). Prepreg manufacturing enables the production of complex integral parts with high quality and adequate fiber volume fraction such as the Airbus Helicopters H145 Fenestron ${ }^{\mathrm{TM}}$ shroud presented in Weber et al. (2016b). When compared to wet hand lay-up, where the resin is applied by hand during part production, the prepreg material has its resin already applied, thus allowing fast and reproducible lamination with minimal manufacturing scatter and reduced porosity (Johnston, 1997).

Nevertheless, the autoclave curing and consolidation are rather complex. Heating ramps, exothermic polymerization reaction, resin flow and resulting roving impregnation, consolidation and resulting thickness variations, ply movement, and tool part interaction are the major phenomena that must be considered when analyzing the autoclave curing process. The high level of complexity does not allow analytical studies. Only the application of sophisticated MPS that is capable of capturing the named phenomena enables the prediction of the manufacturing outcome (Dodwell et al., 2014).

MPS can be used in many different frameworks. First, it may help to improve the manufacturing process (Xie et al., 2012). Different autoclave cycles can be analyzed to increase part quality by reducing temperature gradients during production or to develop and evaluate solutions for a faster heat-up, which reduces manufacturing times and cost (Xie et al., 2012). Pressure gradient and magnitude can also be adjusted to aid the consolidation process and to reach the correct part thickness with minimal porosity (Hubert, 1996). MPS can be used for sensitivity analysis in order to define the optimal autoclave temperature and pressure cycle. 
MPS also provides feedback to the part design in regard to feasibility and producibility of a part. A new part design is worthless, if it cannot be produced efficiently. Complex part designs may require sophisticated molds which cannot ensure repeatability of the process outcome, so that the scrap rate might be too high for economic production. Even if the manufacturing process can be stabilized, it is possible that not all quality criteria are met. This is where MPS plays a major role by being able to predict whether the desired quality criteria can be reached. The simulation enables the evaluation of process stability, and case studies reveal how design changes will impact the manufacturing process as well as their influence on feasibility and producibility.

Another major objective of MPS is the optimization of the molds (Weber \& Balvers, 2015; Weber et al., 2016b). Thermal simulations predict the heat-up and temperature homogeneity throughout the curing process (Weber \& Balvers, 2015; Weber et al., 2016b). They reveal hot and cold spots and the best positions for placing thermocouples to control the autoclave and to gather data for quality checks. The simulation may also reveal cold spots resulting from the mold design. Removal of such spots cannot only decrease the manufacturing times but also increase the temperature homogeneity and so have a positive influence on part quality (Johnston, 1997; Svanberg, 2002).

Another important point is the ability to perform sensitivity analyses and case studies. If different mold concepts are suitable to manufacture the same part, the simulation will provide quantitative data that supports the selection process. A case study is presented later in this paper.

The compaction can also be analyzed to provide important data for mold optimization. When the tool-part-interaction is included in the simulation, the results will show how the thermal expansion of the mold influences the thickness of the part and possible fiber wrinkling due to pressure stresses introduced into the fiber during production. Such information helps to select the best possible material for the autoclave mold. Sometimes the material selection is a trade-off between low fiber wrinkling risk versus smaller process induced deformation (both depending on the thermal expansion of the mold) or fast heat-up versus better temperature homogeneity (influenced by the mold material as well). Thermal and compaction simulation generate the required knowledge for mold optimization and material selection.

The prediction of process induced deformations (PID) is another vital step for the tooling design. If the deformed shape (as-built geometry of the part) is known, it can be compared to the desired part shape (as-designed) and the mold adjusted to 
compensate for PID (Brauner, 2013). This will then be done before the first part is even produced. Older techniques not relying on simulation used statistical data from the first manufactured parts to derive the differences between as-built and asdesigned geometry leading to much higher cost and sometimes even re-design of already existing molds. By means of MPS, PID becomes much more predictable and mold compensation can be accomplished during the virtual design phase of the mold reducing both non-recurring as well as recurring costs.

As already described for the sheet metal forming simulation, the greatest benefit of MPS is the prediction of the manufacturing outcome long before the first part is produced. These capabilities allow an adjustment of the part design, the production process as well as the mold design to ensure stable processes and optimal part quality with the lowest possible manufacturing times and costs (compare Figure 1).

To cover the complete autoclave cycle and all mentioned phenomena, the simulations are very often split into separate simulation modules run in sequence (Brauner, 2013; Weber \& Balvers, 2015). Figure 5 provides an overview of such a sequential thermomechanical simulation process. As soon as a first digital model (computer aided design - CAD) of a new composite part is available, a tooling concept can be developed and subsequently, MPS may be launched.

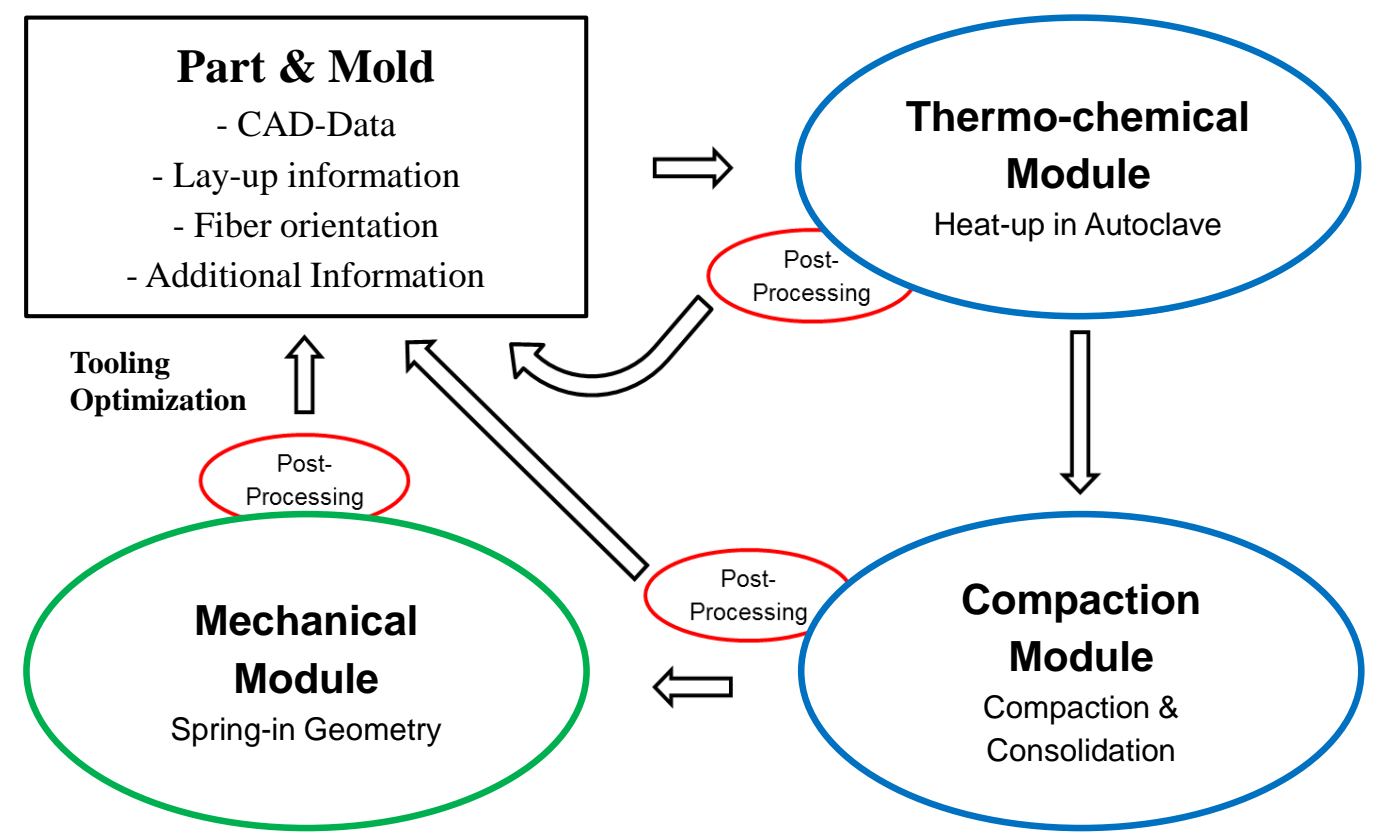

Figure 5. Typical simulation process for autoclave prepreg manufacturing (adapted from Weber \& Balvers, 2015) 
The first step of such a simulation procedure is always a thermal simulation in order to obtain the temperature and degree of cure distribution. This step is necessary, because the heat-up in the autoclave is often very inhomogeneous and the temperature and degree of cure influence the material behavior of the composite parts as well as the tool-part-interaction (Brauner, 2013; Weber \& Balvers, 2015; Weber et al., 2016b). An adequate representation of the non-linear material behavior during cure is therefore a prerequisite. The applied cure kinetic model as well as the specific heat capacity and the thermal conductivity of the resin (both dependent on the degree of cure and the temperature) play an important role in this type of simulation (Brauner, 2013; Weber \& Balvers, 2015; Weber et al., 2016b; Johnston, 1997).

Even more challenging than the selection of appropriate material representations is the generation of the necessary boundary conditions that represent the heat transfer between autoclave air and tooling or part surface (Weber et al., 2016a; b). The major means of heat transfer in an autoclave is forced convection caused by the autoclave airflow (Johnston, 1997). Forced convection is influenced by the flow speed, the degree of turbulence of the flow as well as temperature and pressure of the flowing air. Since outer tooling shapes and autoclave loading conditions may vary strongly, the autoclave flow and thus the heat transfer between flow and tooling will vary as well (Johnston, 1997).

Johnston (1997) neglects the influence of flow phenomena like stagnation and shadowing and only uses the temperature and pressure dependence of the HTC. As a result, all mold and part surfaces have the same HTC independent of their angle toward the airflow and the loading condition of the autoclave. In order to be able to recognize flow effects as well as the loading condition Xie, Lui, Zhang, and Sunden (2012) use complex computational fluid dynamics (CFD). They numerically analyze the behavior of the autoclave flow and perform a thermal simulation based on that flow representation. With correct calibration and verification of the thermal simulation against flow measurements in the autoclave, CFD simulations will render accurate results of the heat-up (Xie et al., 2012). However, the complexity of the simulation and the necessary model set-up limit its applicability on an industrial scale.

A semi-empirical approach for fast boundary condition estimation was developed by Weber, Arent, Münch, Duhovic, and Balvers (2016a) and implemented in a thermochemical simulation in ABAQUS ${ }^{\text {TM }}$ to combine high accuracy with low modeling effort. This so-called shift-factor approach tries to incorporate flow effects by simply shifting a measured reference curve to higher or lower HTC values (Weber et al., 2016a). The reference curve is determined by measuring the HTC progression in the center of an empty autoclave during a complete cycle. The shift 
factors are determined by measuring the HTC on different mold surfaces and different positions in the autoclave for representative loading conditions. Summarizing this data will provide a catalog of shift factors for a vast variety of flow conditions within the autoclave. The HTC boundary conditions can now be estimated for every single mold surface by comparing its angle toward the flow as well as its position in the autoclave and the current loading condition to the reference cases provided in the boundary condition catalog. In conclusion, the shift factor approach allows a fast model set-up and can even analyze different loading conditions. Its accuracy is slightly lower than that of a CFD simulation but it is easily applicable on an industrial scale (Weber et al., 2016a).

The second module is very often a compaction module that considers resin flow, consolidation, and mechanical behavior of the fibers in thickness direction. Prepregs are mostly described by means of percolation flow which is governed by Darcy's Law (Dave, Kardos, Dudukovic, 1987; Hubert \& Poursartip, 1998; Hubert, 1996). Darcy's Law requires the knowledge of permeability and viscosity of the liquid resin. Permeability is mainly influenced by the fiber volume fraction, while viscosity depends on the temperature and the degree of cure progression (Dave et al., 1987; Hubert \& Poursartip, 1998; Hubert, 1996). In addition to Darcy's Law, the non-linear elastic behavior of the fiber bed can be described by an equation often referred to as the Gutowski equation (Gutowski et al., 1987). It describes the exponential increase in stiffness when increasing the fiber volume fraction during consolidation (Gutowski et al., 1987).

The material behavior is often summarized in the so-called spring-pistonanalogy (see Figure 6). When compaction starts, the resin can flow out of the piston, a process governed by permeability and viscosity. The more resin leaves the piston the more the spring (fiber bed) will be deflected. Increasing the compaction of the fiber bed will increase its stiffness. Therefore, more and more load is carried by the fibers and the pressure in the resin decreases until the total load is supported by the fiber bed alone. A detailed explanation of the analogy can be found in Dave et al., (1987), Hubert \& Poursartip, (1998), and Hubert, (1996). 

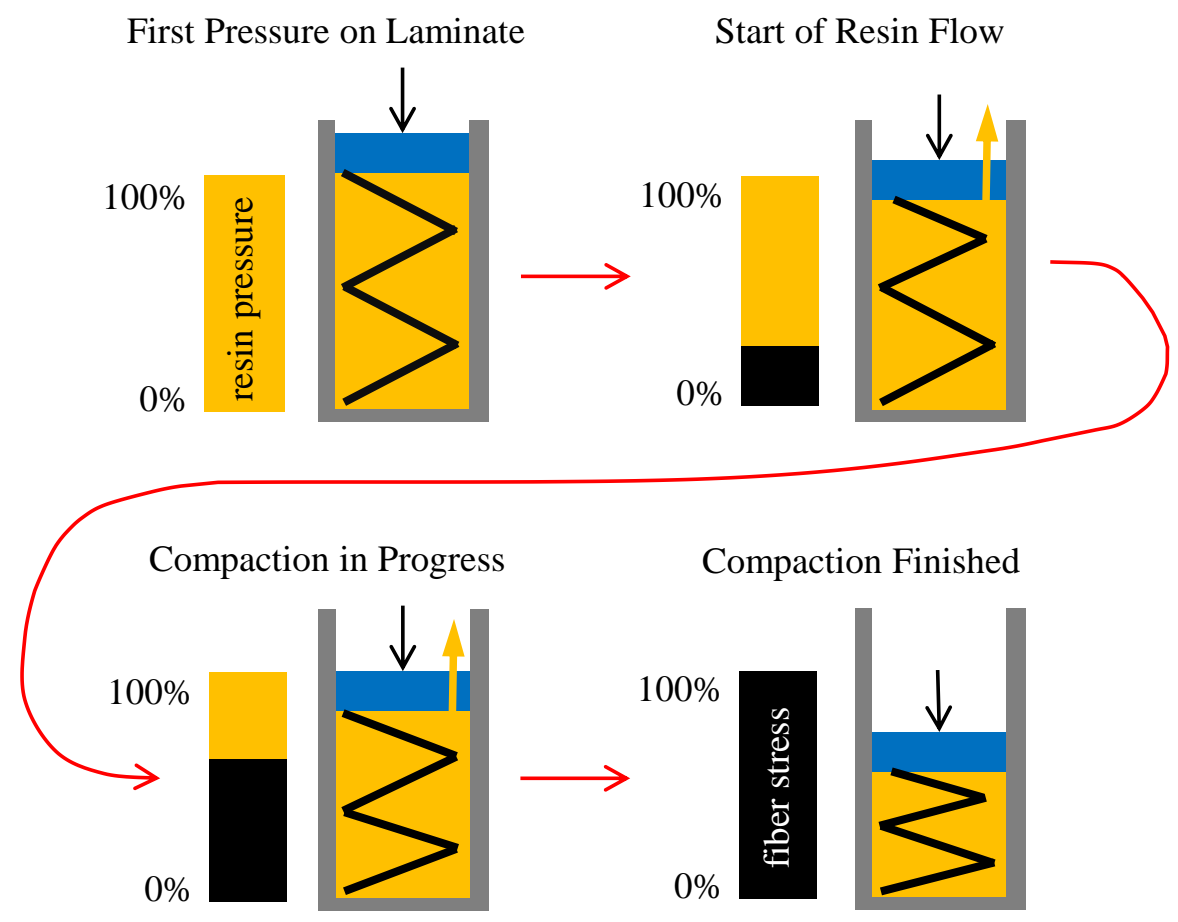

Figure 6. Spring-Piston-Analogy as seen e. g. in (Dave et al., 1987; Hubert \& Poursartip, 1998; Hubert, 1996)

As already stated for the thermal simulation, a material characterization is most important for all modules of the MPS in order to achieve accurate simulation results. Implementing the non-linear material behavior into a FE simulation enables the prediction of part thickness, fiber volume fraction, and resin pressure progression even on a local level. However, the simple approach with Darcy's Law and the Gutowski equation is limited to fully saturated prepregs (Hubert, 1996). More sophisticated methods that expand far beyond the horizon of this paper are necessary to simulate unsaturated prepreg materials.

To enhance the informative capability of the simulation, the tool-part-interaction (friction between mold surfaces and prepreg ply) as well as the interlaminar friction between the plies can be added to it. This can be done by means of shear layers (Johnston, 1997) or standard FE contact formulations as provided for example by ABAQUS ${ }^{\mathrm{TM}}$. The elements of the shear layers enable a high shear deformation in the contact zone to approximate the relative movement between mold surface and plies. The contact formulations rely on friction coefficients and shear limits to provide interface shear forces and a relative movement between mold surface and first ply without unrealistic shear deformation in the interface element layer (shear layer) (Özsoy, Ersoy, \& Wisnom, 2007). 
The friction interaction between mold surface and plies is rather complex, since it is not a pure Coulomb friction but combines Coulomb and hydrodynamic friction depending on temperature, viscosity and degree of compaction (Weber, Tellis, \& Duhovic, 2016c). However, the information content makes the experimental characterization of the friction phenomena and their implementation into the simulation worthwhile. Especially, when tooling design optimization is a major goal, the tool-part-interaction should be included in the MPS. Thermal expansion of the mold as well as its mechanical interaction with the prepreg (movement of mold parts during consolidation) will influence final part thickness, fiber volume fraction distribution, and dimensional accuracy. If the tool-part-interaction is included in the simulation, these influences can be predicted and accounted for during tooling optimization. Furthermore, the fiber wrinkling risk due to consolidation over convex radii may be evaluated, when interlaminar friction is considered as well (Dodwell et al., 2014).

The final module of the simulation will provide the part's geometric deformation during curing. As shown by Svanberg (2002), the curing of thermoset material results in so-called process induced deformations (PID). They can be in the range of up to several millimeters depending on part size, material, laminate layup, curing process, and tooling material (Svanberg, 2002). A lot of different techniques may be employed to predict PID ranging from stand-alone phenomenological approaches up to a full MPS using thermal and compaction simulation in advance to cover all previously mentioned aspects (Johnston, 1997). Due to the complexity and large variety of different methods it is outside the scope of this paper to provide explanations for all of them. Interested readers should refer to Johnston (1997), Svanberg (2002), and Brauner (2013) for further information.

\section{Simulation on an Industrial Scale}

\section{Metal Forming Simulation}

In order to use a forming simulation on an industrial scale a compromise between accuracy and time consumption must be found. Depending on the stage of the design process, different levels of accuracy might be appropriate. In an early concept study low accuracy can be accepted in order to have a fast simulation that allows sensitivity analysis and concept studies. When the simulation is used for a final process or mold qualification, the most accurate approach should be selected, even if it increases the simulation time significantly.

Independent of the chosen approach, forming simulation usually follows the real process and models the simulation steps in direct correlation to the production 
process (compare Figure 7). In order to apply the available simulation capabilities efficiently on an industrial scale, explicit and implicit integration schemes are used in combination (Maker \& Zhu, 2000; Maker, \& Zhu. 2001). Highly non-linear forming or cutting steps with large deformations are simulated with explicit time integration, whereas the more linear ones for spring-back prediction make use of implicit time integration (Maker \& Zhu, 2000; Maker \& Zhu. 2001).
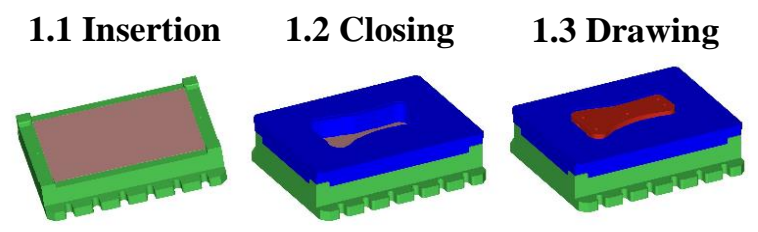

\subsection{Opening}
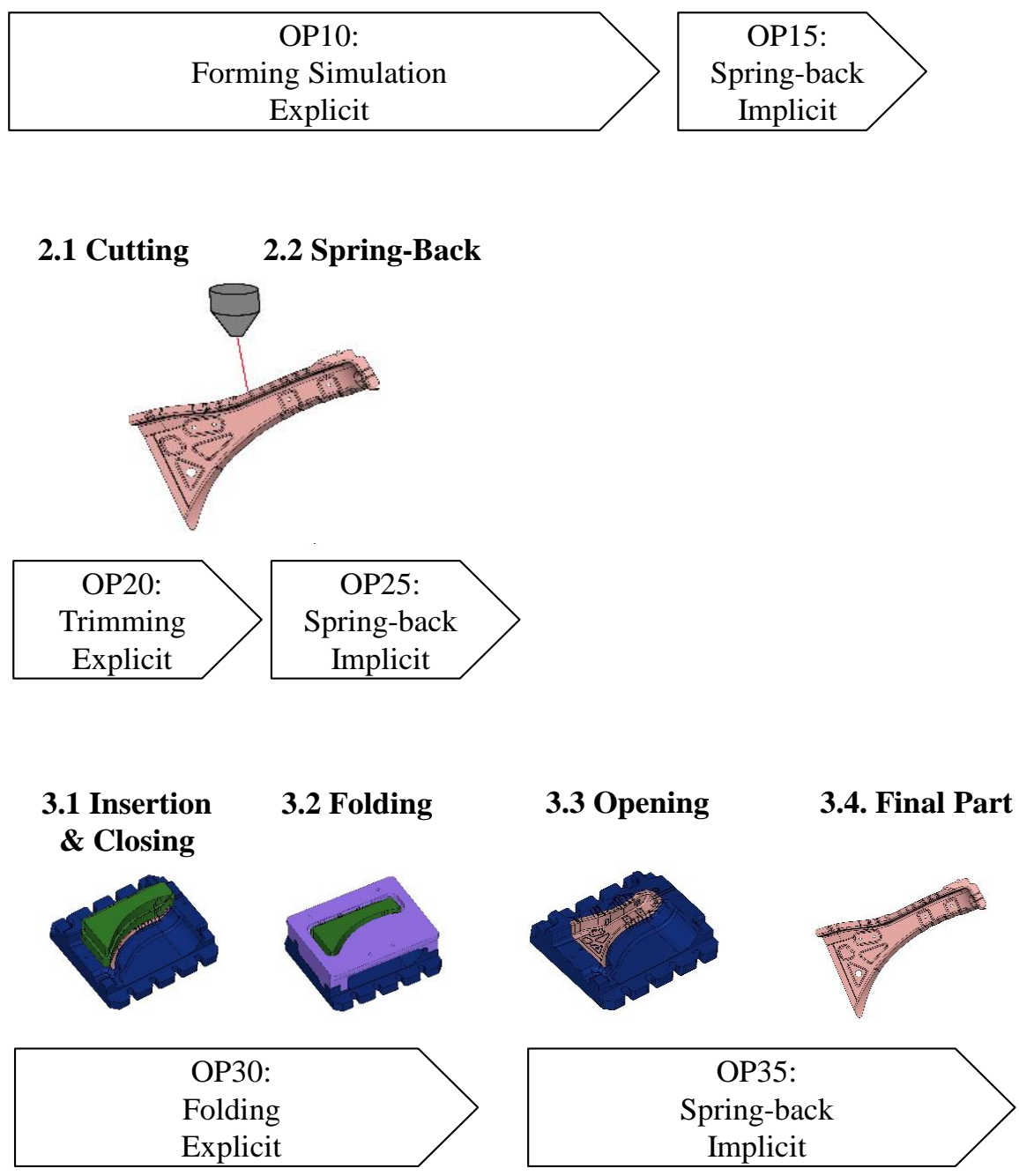

Figure 7. Real multistep forming process including simulation steps 
Each simulation step leads to a deformed blank mesh with a thickness distribution and corresponding hardening values. Analyzing those results helps to optimize the manufacturing process and the mold. Additionally, thickness and hardening values may be transferred to structural simulations in order to justify product functions related to elasticity and strength. Even crash simulations in the automotive sector can benefit from the process simulation results. Accurate forming simulation results can also be used to determine the as-built geometry. Compensation actions to reduce the deviation between as-built and as-designed shape can be tested virtually, as a result avoiding costly physical tests and re-work loops (compare Figure 1).

In order to compare thickness and spring-back values (simulation to simulation or simulation to measurement) for an entire part, the post processing tool must be able to detect which points of the different results belong together. One option is to resort to a run-length approach, assuming the different spring back results are only caused by the elastic portion of strain. In this manner, multiple data sets related to the position (e.g. thickness and yield values) are collected, compared, and used to evaluate different approaches to derive the optimal compensation action (Najafi et. al., 2001). Spring-in angles and thickness distributions are thus derived and compared quickly without intensive manual post-processing.

Such a software tool is especially useful for performing sensitivity analyses and parameter studies on an industrial scale, since it allows a fast and automated evaluation of the simulation results. Changes in mold shape as well as draw bead shape and positioning can be evaluated to reduce spring-in and to optimize the overall manufacturing outcome in terms of thickness variations, for example. Apart from adjusting the tooling geometry, manufacturing parameters (binder forces, forming speed, etc.) can also be optimized by comparing the as-designed shape to the as-built parts by means of the described software tool.

In addition to comparing just one model to another, several simulations and measurements enable the evaluation of the process and/or simulation robustness by the value of scatter. Such a tool can therefore also be used to optimize the simulation accuracy itself or to verify a simulation by comparing simulation results to measured results.

In total, a post-processing tool is a real asset for improving part quality as well as the reduction of manufacturing costs by decreasing physical improvement loops of the tooling shape and by minimizing test runs in order to find the optimal parameter set for manufacturing. 


\section{Composite Materials Simulation}

As already mentioned in reference to the metal forming simulation, the application of MPS on an industrial scale is always a compromise between accuracy and time consumption. The most important aspect is that all predictions made by the MPS are reliable and reproducible. The metal forming simulation already showed that deviations between simulation and measurement are to be expected. However, only simulations that yield results close to reality will help improve autoclave manufacturing. Sufficient accuracy can be assured by rigorous testing and validation of the simulation as performed in the second part of the sheet metal forming simulation case study and for example by Weber et al. (2016a \& 2016b) who tested their shift factor approach for thermal simulation on different levels of complexity. Reliability of the simulation can only be guaranteed after comparing simulation results to a lot of test data generated under realistic manufacturing conditions and covering all possible deviations from the standard process.

When reliability is ensured, the simulation has to become efficient. For the metal forming simulation the authors improved post-processing, whereas for the composite manufacturing simulation the focus is on optimizing pre-processing. Model set-up times (geometry simplification, meshing, application of boundary conditions, etc.) as well as solution times of the ABAQUS ${ }^{\mathrm{TM}}$ solver must be reduced to a minimum to gain viable knowledge with minimal effort.

If the complete development time of an autoclave mold is only six weeks, the numerical analysis of its heat-up should not take two months. The simulation would be useless for an industrial application. Consequently, the simulation has to become as simple as possible without sacrificing its accuracy and automation of the model set-up should be applied wherever possible. Figure 8 shows how two automation scripts may be applied to reduce the effort for model set-up. Tasks like creating material representations and entering the necessary parameters as well as the insertion and combination of the meshed parts to an assembly can be automated. After defining the mold surfaces with different heat transfer coefficients, the correct boundary conditions can also be applied automatically by means of an additional Python script. 


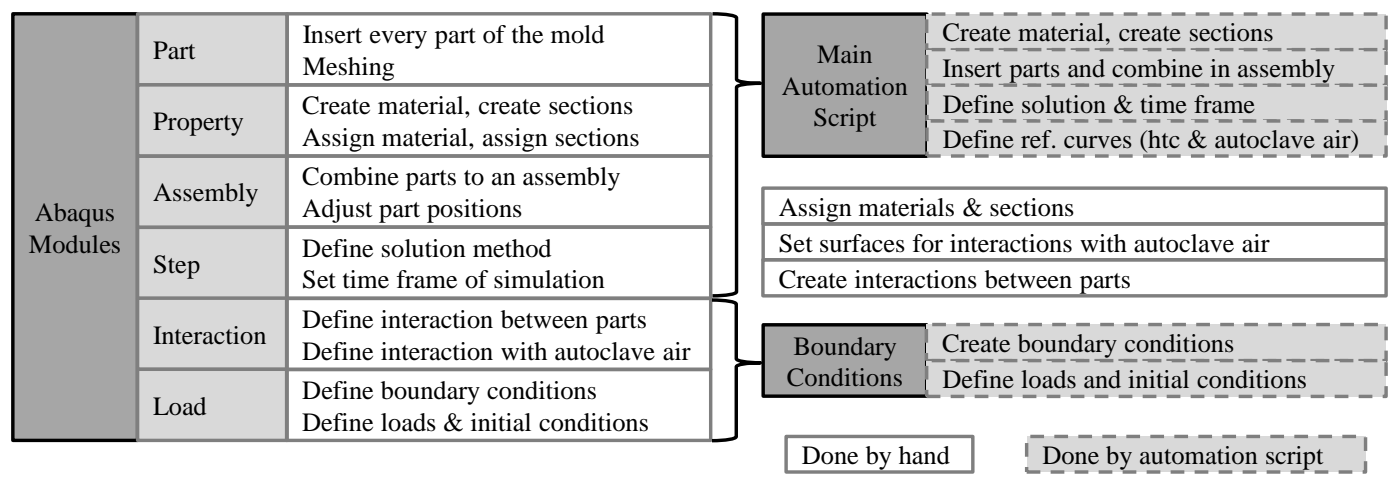

Figure 8. Steps of model set-up by hand (left) versus automated model set-up with two automation scripts (right)

This kind of automation unfortunately only reduces the model set-up times within the simulation software. Meshing and solution times will be unaffected. Figure 9 provides an overview of the possible reductions in model set-up times by the use of automation scripts.

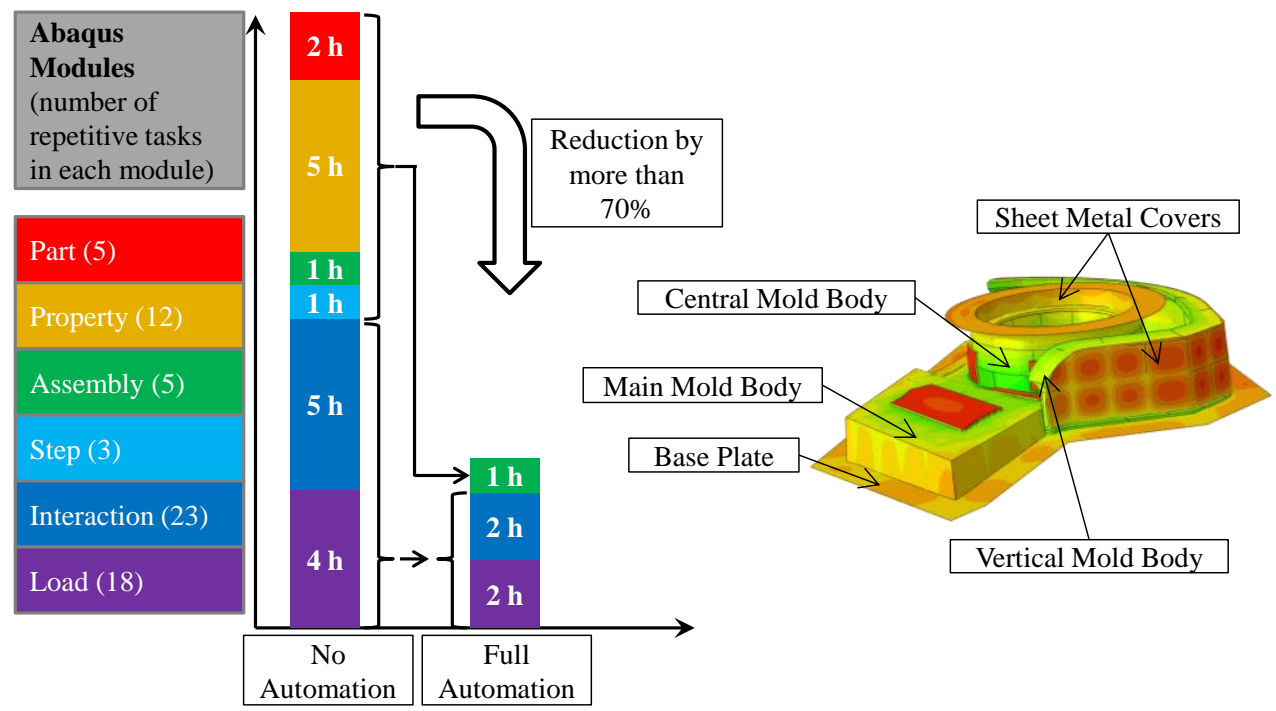

Figure 9. Time reduction in model set-up for a representative mold consisting of five major components

Meshing times can be reduced by utilizing the automated meshing capabilities of commercial meshing software tools and excepting lower-than-standard element quality parameters. Minimal limits for the quality parameters should be derived during the simulation verification. The major goal must be to reduce meshing 
time without sacrificing accuracy. If accuracy is lost by using an automated meshing resulting in lower-than-standard element qualities, it should not be allowed andre-work on the mesh has to be done. Nevertheless, this approach enables a suitable reduction in meshing time.

Reduction in calculation time of the FE-solver can be achieved by generating either a coarser mesh or a reduced number of integration points, if a shell mesh is used, for example. As stated before, the reliability and accuracy of the simulation should not be impacted by the time reduction. As a consequence, it must be verified that a coarse mesh will not lead to any loss in accuracy and limits for maximum element sizes should be defined.

Sensitivity analyses performed by the authors revealed that one integration point over the thickness of a ply or a thin-walled mold section provides sufficient accuracy for thermal simulation. The maximum simulation error increases from $8.2 \%$ to $8.4 \%$ while the calculation time is reduced by a factor of 2.5 . The maximum element size was increased from $5 \mathrm{~mm}$ to $20 \mathrm{~mm}$ reducing the solution time by an additional factor of 4.0 and increasing the maximum error from $8.4 \%$ to $8.5 \%$ in the examples. Altogether a reduction in working time (model set-up plus solution time) to approximately $35 \%$ of its original duration can be achieved through the use of all the named methods. In terms of accuracy, the overall maximum error increased from $8.2 \%$ to $8.5 \%$ and remains well below the limit of $10 \%$, which can be considered adequate when taking material non-linearity into account.

The following case study shows an example of the application of the industrialized simulation approach. A thermal evaluation of two different mold concepts is performed with the goal of selecting the most suitable mold design for a fast and homogeneous heat-up.

\section{Case Studies}

\section{Metal Forming Simulation}

As a first step, a feasibility study was performed to determine the manufacturability of a demonstrator part made of DC04 mild steel. Due to the complex shape of the final part with undercuts it has to be formed in multiple steps according to Figure 7. Several blank designs were tested to locate critical areas in the part during the manufacturing process. The evaluation results are presented in Figure 10. 

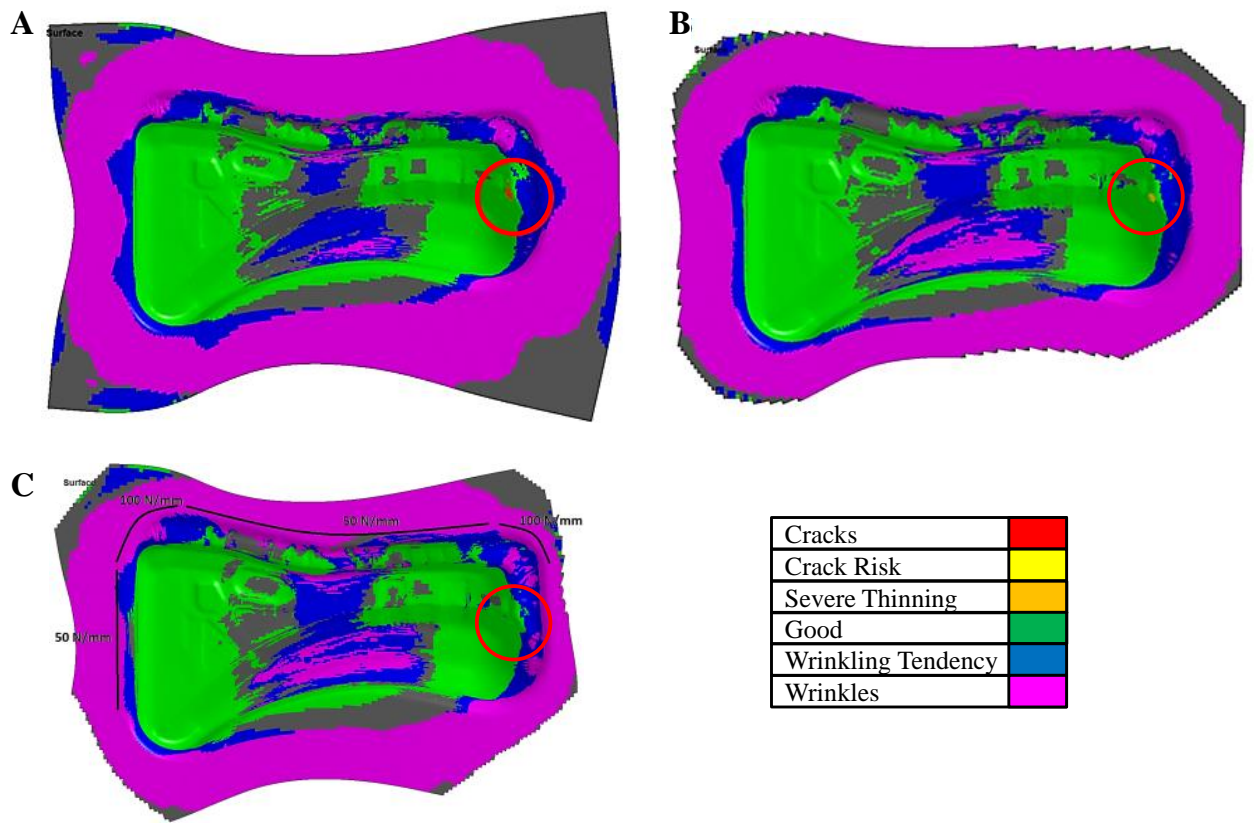

Figure 10. Forming results of demonstrator part with varying process parameters

Several critical positions in the part can be observed in all the blank designs. Since the outer flange is trimmed in the following step (step 2.1 or OP20) this region is of minor importance. Nevertheless, there are wrinkling problems in the upper flange and on the vertical edge shown by blue and purple colors. There is also a position prone to cracks on the right-hand side of the part in Option A indicated by the red color (circle in Figure 10A). By changing the binder force and the blank geometry iteratively an improvement can be achieved as shown in Figure 10B. The crack is reduced to an area of severe thinning (changed color from red to orange).

Further simulations revealed that only the application of draw bead can avoid cracks and severe thinning in that area. Nevertheless, the wrinkling tendency in flange and vertical edge area increased from option A to B and remain almost unchanged from $B$ to $C$ (Figure 10). In conclusion, this part cannot be manufactured in one fraction. It was therefore decided to manufacture only the central part shown in Figure 11 and to attach the outer portions in a following assembly step or redesign the surrounding parts accordingly. In this particular case the feasibility study showed that even an optimized production process and mold will not be sufficient to manufacture a part which satisfies quality requirements. This simulation study thereby avoided a costly trial-and-error process that would ultimately have come to the same conclusion. 


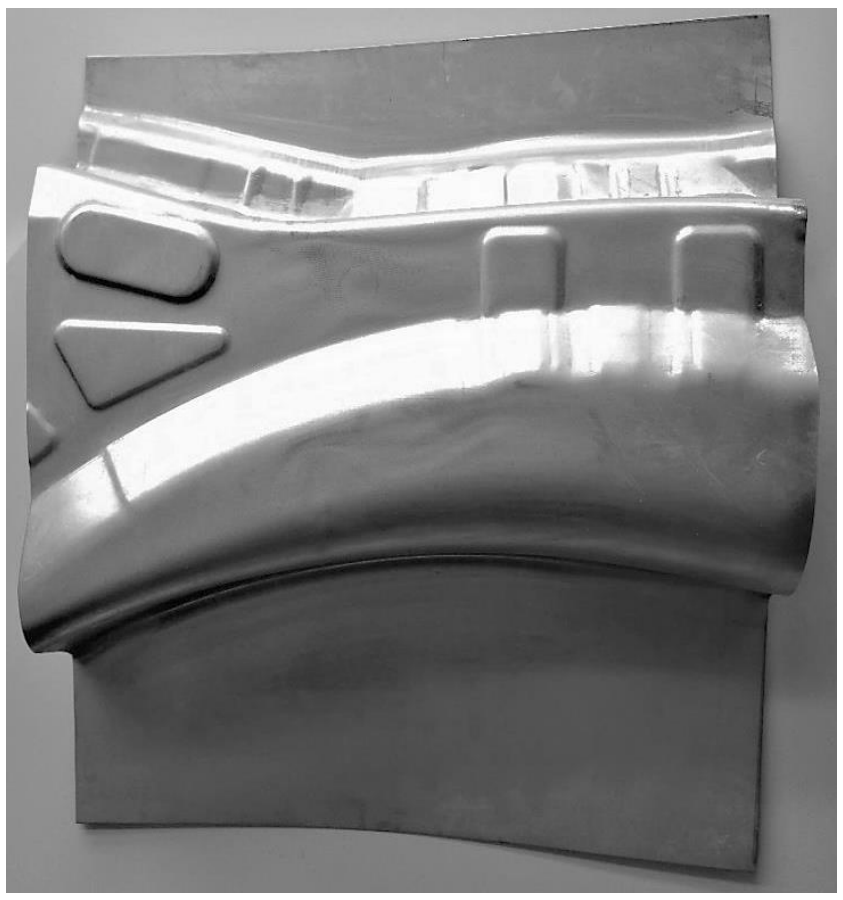

Figure 11. Manufactured central portion of the demonstrator part

In order to assess the accuracy of the simulation and to provide an estimation of possible deviations from reality, the developed software tool was used to compare the accuracy of several material models and tooling representations. The DC04 mild steel material of the demonstrator was originally qualified for a Hill ' 48 yield criterion that is used as a special case of the Barlat' 89 yield criterion (Baiker, Helm, 2012). Three simpler material models can be derived from the qualified one and are shown in Table 1.

Furthermore, two different tooling representations were compared. The first representation was an as-designed shape of punch binder and die. The second was a measured geometry after grinding the surface. Each tooling representation was combined with each material model leading to eight different simulations which were compared to the mean of seven manufactured parts.

For a fast evaluation of the simulation accuracy, averaged values for the error in thickness distribution were calculated by means of the previously described software tool. The comparison of spring-back angles was done separately for each relevant angle. The results discussed here are derived from the spring-back step after cutting the part (OP25 in Figure 7). 
Table 1

Material models used in case study

\begin{tabular}{ccccc}
\hline $\begin{array}{c}\text { Material } \\
\text { model in } \\
\text { LS-DYNA }\end{array}$ & Yield locus & Anisotropy & Hardening & $\begin{array}{c}\text { Estimated } \\
\text { CPU time }\end{array}$ \\
\hline 24 & Von Mises & No & isotropic & Low \\
36 & Barlat'89/Hill'48 & $\begin{array}{c}\text { Transversal } \\
\&\end{array}$ & kinematic & medium \\
& & planar & & \\
$36 \_i$ & Barlat '89/Hill48 & No $(\mathrm{R}=1)$ & kinematic & medium \\
37 & Hill'48 & transversal & isotropic & medium \\
\hline
\end{tabular}

None of the material models show a significant influence on the thickness prediction accuracy. Every combination of material model and tooling representation results in an overestimation of thickness of approximately $8 \%$ above the mean of the measured parts. The $8 \%$ deviation of the thickness corresponds to approximately three standard deviations of the measured data set from seven parts. Therefore, the deviation in thickness prediction is not a result of measurement scatter but of systematic simulation error.

A best fit of the mean measured geometry and the simulation results is performed to compare the geometrical deviations of simulation and measurement. Then several section cuts are created and compared automatically by means of the post-processing software tool previously described.

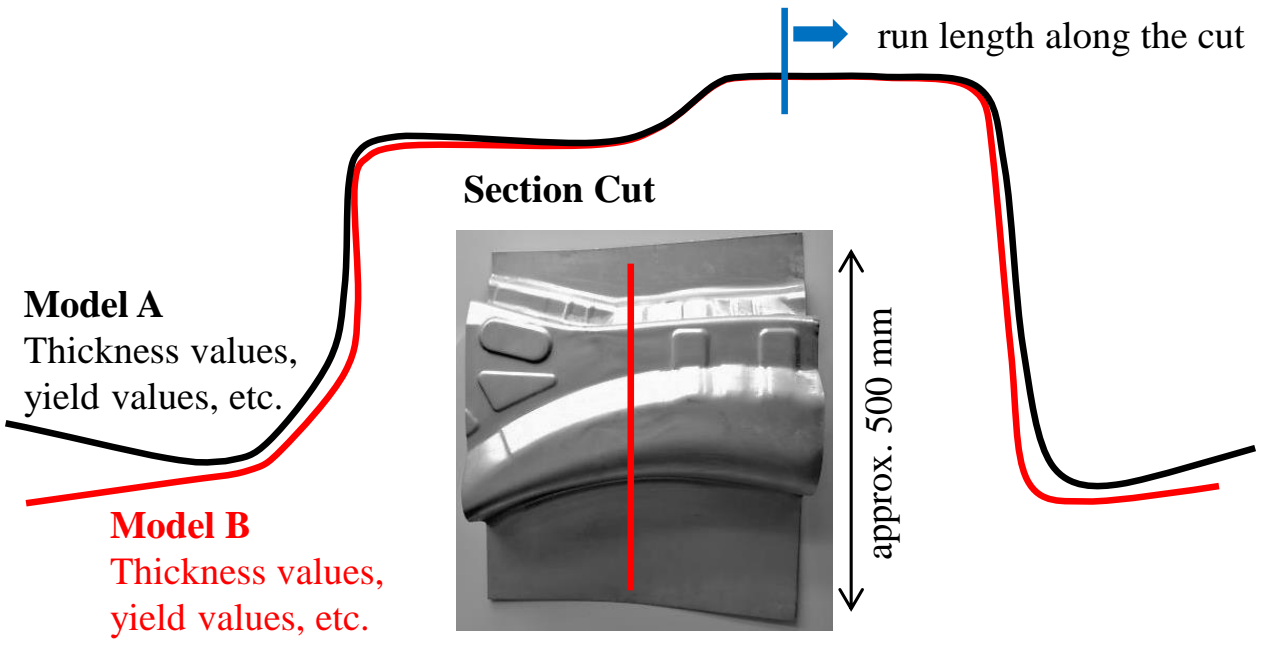

Figure 12. Manufactured central portion of the demonstrator part 
The mean distance between simulation and measurement is $1.6 \mathrm{~mm}$. MAT 36_i in combination with the measured tooling geometry results in the smallest error of $1.4 \mathrm{~mm}$, whereas MAT 37 applied together with an as-designed tooling shape result in the maximum error encountered $(1.8 \mathrm{~mm})$.

In Figure 13, the propagation of the spring-back angle is displayed exemplarily for one of the curved flanges. The spring-back angles for the ideal tooling geometry show a much larger discrepancy to the measured result (approximately $3^{\circ}$ ) than the simulation results attained with a measured tooling surface (approximately $1,2^{\circ}$ ). Beside the improvement of the discrepancy, the application of the measured tooling geometry within the simulation reduces the scatter between the different material models to $1^{\circ}$ from a maximum of $2^{\circ}$. However, when the MPS is used in a predictive manner, a measured tooling surface is not available. So, extra care must be taken in the selection of the material model for such predictive simulations.

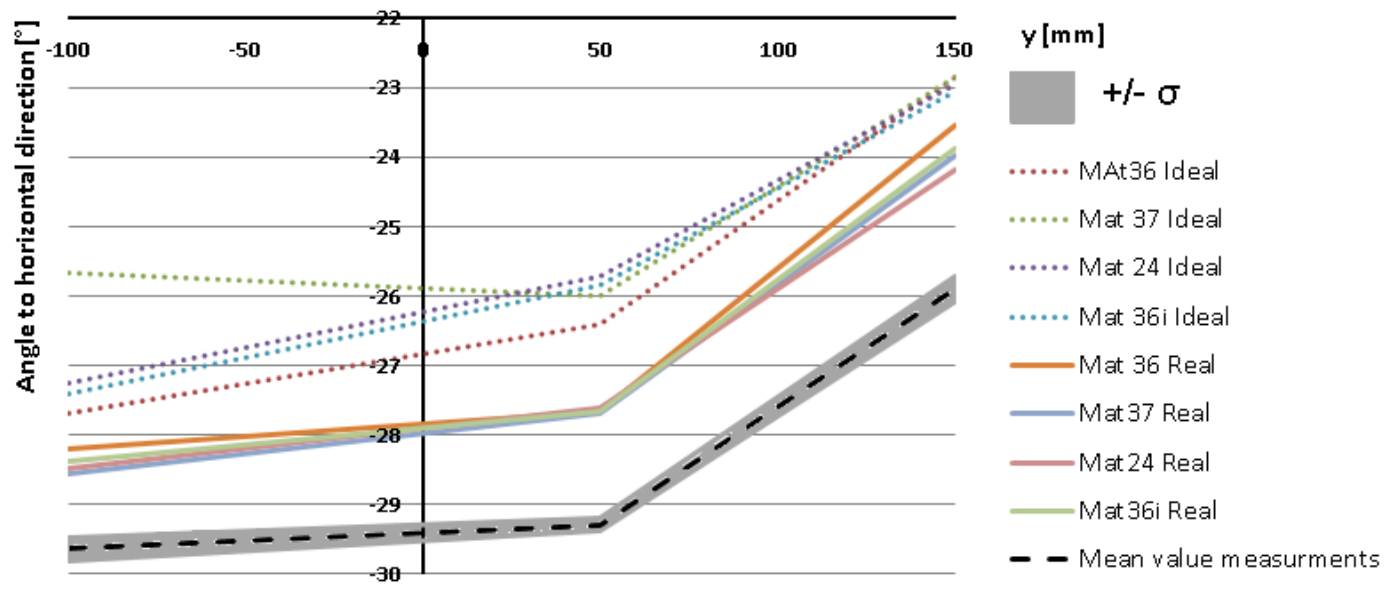

Figure 13. Spring-back angle result for a curved flange using different material models in combination with an ideal tooling geometry (ideal) and a measured tooling geometry (real)

In summary, the case study provides a first impression of how MPS can be applied in an industrial environment. The feasibility study shows how the simulation supports tooling and process design (parameter studies, comparison of manufacturing concepts) and how costs can be avoided by checking the producibility before selecting a manufacturing concept. The second part of the case study presents the advantages and capabilities of a software tool for evaluating thickness and spring-in angles in an easy and automated way. The gained results provide a first estimate of the achievable simulation accuracy and show the importance of the correct selection and characterization of the material model. 


\section{Composite Materials Simulation}

Two different mold designs may be suitable for the production of the same approximately z-shaped prepreg composite part. Figure 14 shows the two mold concepts at a development stage that would normally call for a conceptual design review. The conceptual design review is the latest possible milestone during a mold development for selecting the optimal production concept. Before MPS was available the tooling designer made his/her decision based solely on experience. With the application of MPS the decision making can be based on quantitative data instead of relying on experience alone (compare Figure 1).
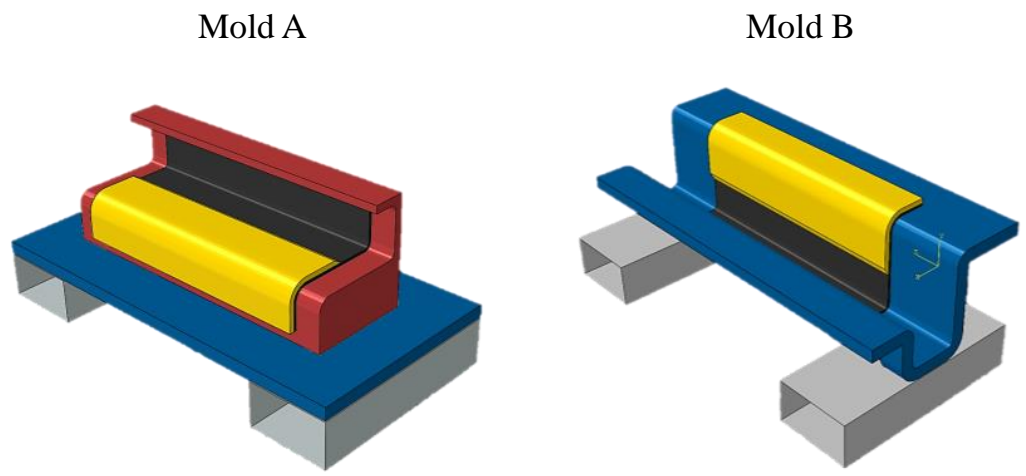

Figure 14. Two mold concepts for the production of the same z-shaped prepreg composite part (basic dimension approx. $600 \mathrm{~mm}$ x $200 \mathrm{~mm}$ ) [mold with separate base plate and core element (a) vs. mold without separate core element (b)]

Both molds are made of invar (FeNi36), which has a very low thermal expansion coefficient that is advantageous for the production of composite parts (reduction of PID). Mold A is normally preferred by the tooling designer, because the shape giving elements (cores on top of the base plate) are separated from the base plate containing all the auxiliary attachments like handling rods, vacuum lines, and thermocouple connectors. This design even allows the splitting of core elements and enables fast mold re-work by just replacing core elements without the need to remove the mold from the production environment. It has, however, major disadvantages concerning heat-up. The separation of core and base plate leads to a socalled "thermos flask". To reduce the weight of the core element and enable easier handling, the core element is hollowed out. Since the complete core is included in the vacuumed volume, the hollow portions of the core will be evacuated limiting the heat transfer between base plate and core to its small ribs (Figure 15). 


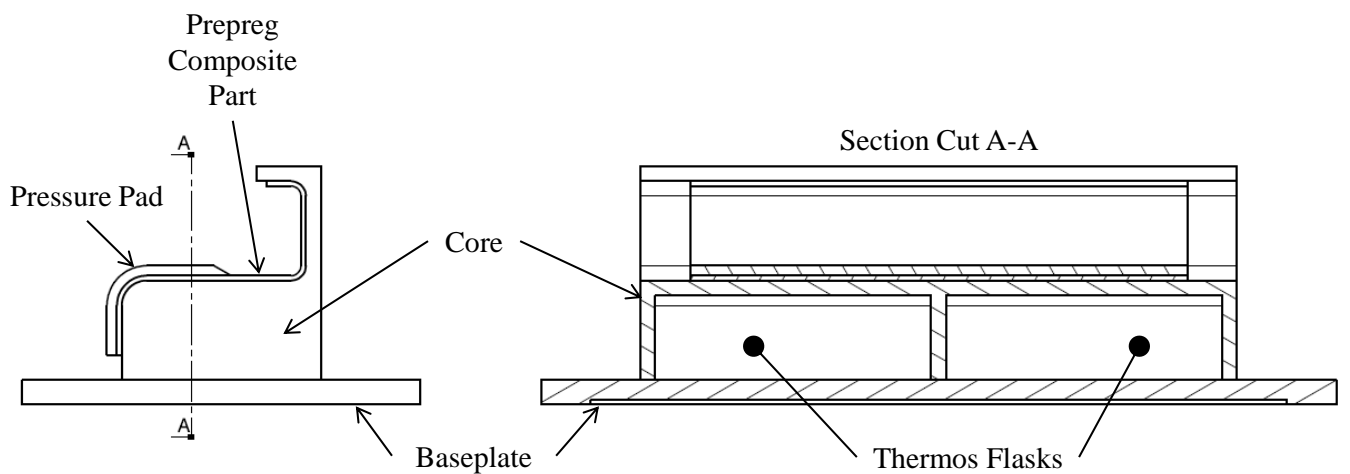

Figure 15. Thermos flasks of mold A

The thermos flasks can be avoided by altering the mold design. Instead of using a flat base plate with separated cores on top, the shape of the part can be modeled into the base plate without the need for any core elements at all (Figure 14b). This results in a thin-walled mold without any thermos flasks or unnecessary thermal mass. The complete mold has approximately the same wall thickness, which has a positive influence on temperature homogeneity. It can be assumed that mold $\mathrm{B}$ will have a faster and more homogeneous heat-up.

However, the improved heat-up comes with some short-comings for the production. Since shape-giving elements and base plate are the same, all handling devices and connectors are attached to the shape-giving element. Furthermore, the mold must be made as one piece to ensure vacuum tightness. As a result, changes to the mold can only be made by removing it from the production line and bringing it into the tooling shop. The question arises whether it is worthwhile to sacrifice fast and cheap changeability of mold A in favor of mold B. Only if mold B has a significantly improved thermal behavior, will it be selected. Since the tooling designer has no way of quantifying the improvements provided by mold $\mathrm{B}$, the selection will most definitely fall on mold A. This is where MPS comes into play. A thermal simulation of both molds applying the same boundary conditions will provide quantitative data about the possible improvements.

The finite element model for the thermal MPS is created in ABAQUS ${ }^{\mathrm{TM}}$ using the automation scripts mentioned before. The complete model set-up time for mold A is two hours plus three hours for meshing. The mesh mainly consists of first order volume elements (DC3D8) with $10 \mathrm{~mm}$ edge length for mold and composite part. Only the handling rods consist of shell elements (DS4) with the same edge length because of their small wall thickness $(4 \mathrm{~mm})$. 
In this case it is assumed that the mold is placed alone and in a central position within the autoclave. As a result, only stagnation and shadowing effects of the mold itself (intra-part shadowing) play any role, while autoclave loading conditions and shadowing produced by surrounding molds (inter-part shadowing) can be neglected (compare also Weber et al., 2016b). An example of the surface selection and the respective HTC distribution on the mold surfaces is provided in Figure 16. The selection of the surfaces and the parameters for the HTC boundary conditions is explained in detail by Weber et al. (2016b).

Material data, autoclave temperature progression, HTC reference curve, etc. are entered into ABAQUS ${ }^{\mathrm{TM}}$ automatically by the aforementioned python scripts. Since the mold consists of separate parts, thermal interactions must be generated between those parts. As shown by Abdelal, Robotham \& Cantwell (2013), ideal thermal conductivity will yield very good results and can be achieved in ABAQUS ${ }^{\mathrm{TM}}$ by means of tied contacts. A detailed description of the model set-up, material modelling, boundary conditions, and all necessary parameters can be found in Weber \& Balvers (2015) and Weber et al. (2016a \& b).
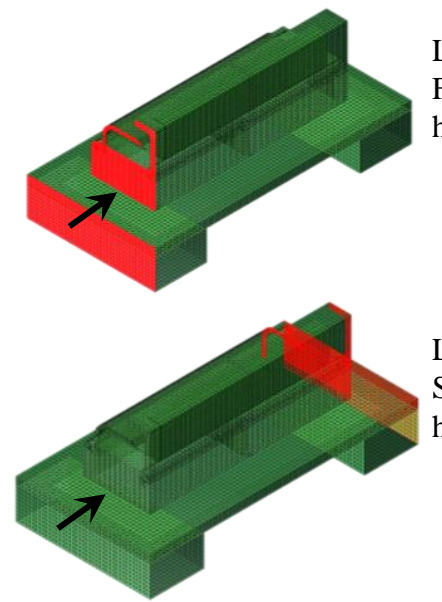

Lee side of the mold

Shadowing

htc $\approx 0.8 \times$ ref. htc

Flow on lower side htc $\approx 0.7 \mathrm{x}$ ref. htc

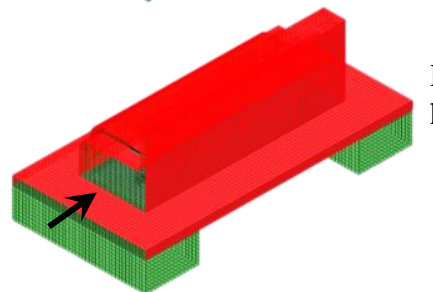

Parallel flow

htc $\approx 1.0 \times$ ref. htc
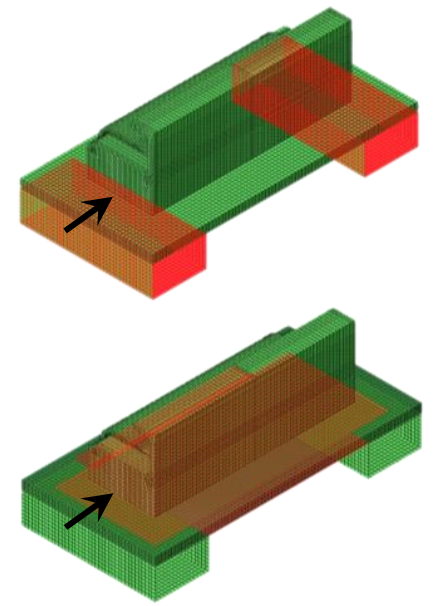

Figure 16. Selected surfaces for boundary condition application and approximated shift factors applied 
Figure 17 shows an overview of the simulation results. The temperature curves given in the diagrams are the autoclave air temperature (black-dotted) as provided by the autoclave during the manufacturing process, the temperature progression of the hottest point of the composite part (solid red), the coldest spot of the part (green-dashed) and the difference between those two (blue-dash-dotted) as a measure for the temperature inhomogeneity. The diagram of mold B reveals that the coldest point of the composite part reaches the desired temperature of $175^{\circ} \mathrm{C}$ (minimal curing temperature) approx. 9\% faster than the part manufactured on mold A. The improvement of mold B compared to mold A is even more distinct, when temperature inhomogeneity is considered. Mold A shows a maximum difference between hottest and coldest spot of the composite part of approximately $44^{\circ} \mathrm{C}$, while mold $\mathrm{B}$ only exhibits an $18^{\circ} \mathrm{C}$ difference resulting in a reduction of temperature inhomogeneity by $58 \%$.
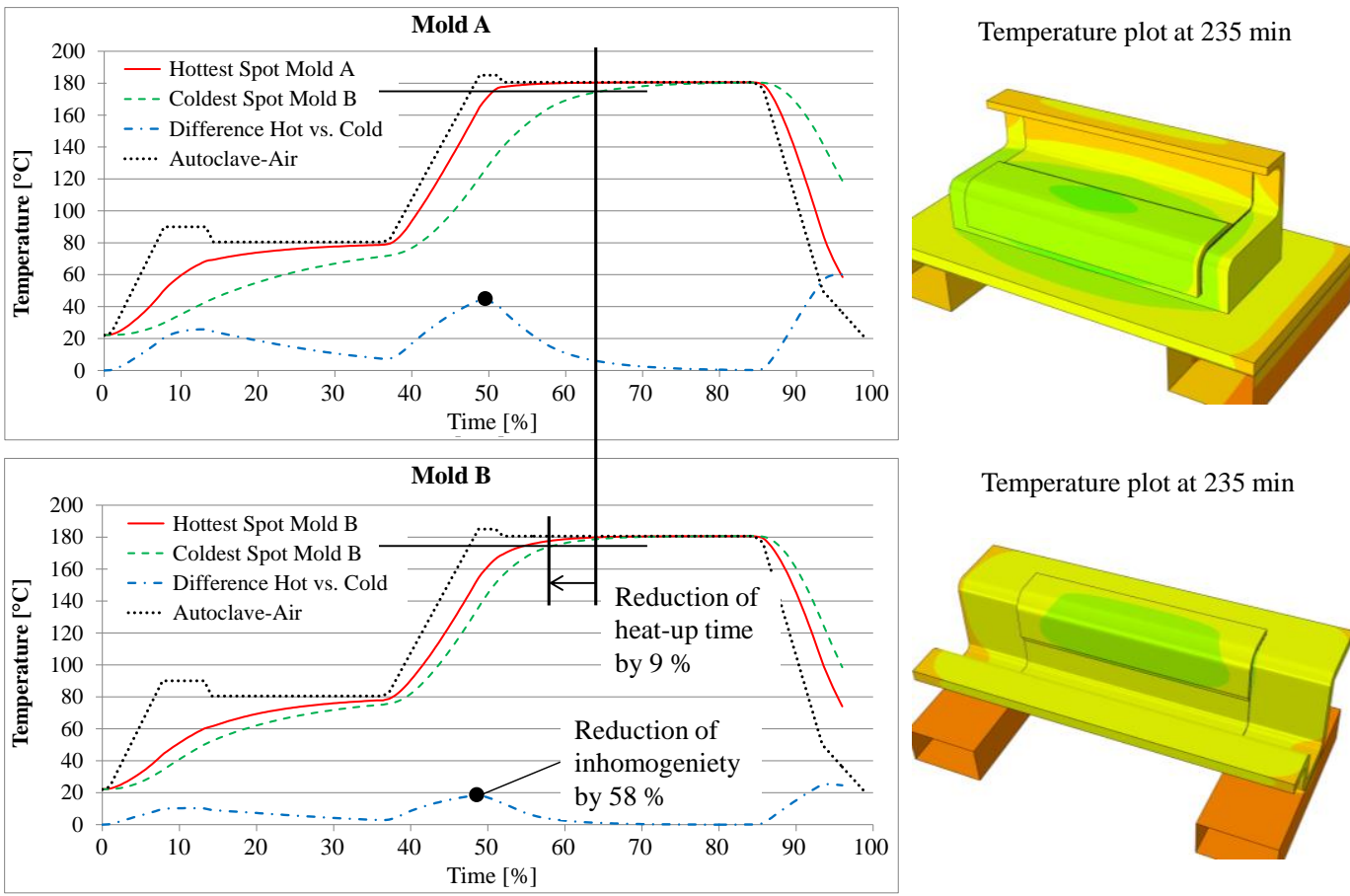

Temperature plot at $235 \mathrm{~min}$

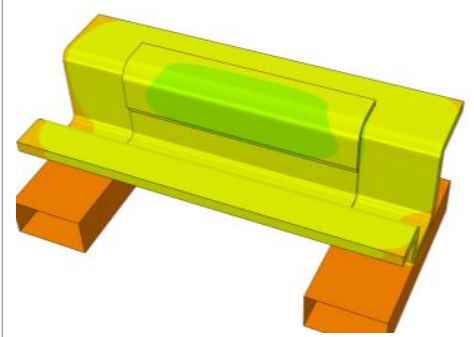

Figure 17. Comparison of temperature distribution in molds A and B

Mold B is obviously the better choice, when heat-up and temperature homogeneity are concerned. However, the question might arise, if a change in flow direction could improve the behavior of mold A. If mold A can be improved in a way to provide a heat-up behavior similar to mold $\mathrm{B}$, the separation of base plate and core element could be retained. This would allow a fast implementation of part 
design and tooling changes by simply replacing the core elements rather than producing a completely new mold. A mold with the thermal behavior of mold B and the changeability of mold A would certainly be the best solution. Figure 18 shows the comparison of three different flow directions for mold A compared to the heatup of mold B. Changing the flow direction only has a minimal effect on mold A. Furthermore, the originally chosen flow direction is one of the best possible for mold A. No further improvements can therefore be reached by altering the autoclave conditions alone.

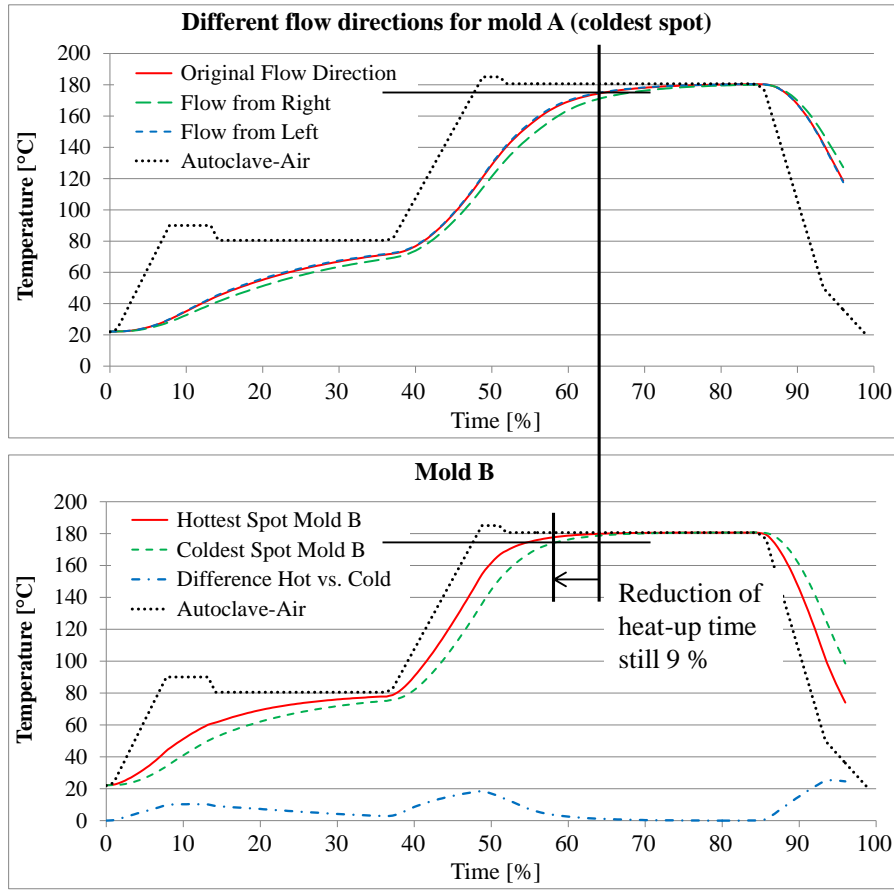

Temperature plot at $235 \mathrm{~min}$ for the original flow direction

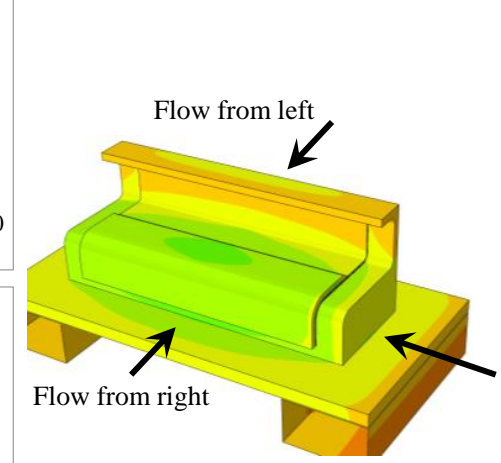

Figure 18. Comparison of three flow directions for mold A

It becomes clear from Figure 18 that changing the orientation of mold A within the autoclave to optimize the flow direction is not sufficient for improving the heating behavior significantly. Mold B remains the correct choice for optimized heat-up and curing.

Mold B, the same as mold A, is made of invar. Invar is most often chosen because of its low thermal expansion coefficient which reduces PID significantly. Assuming PID is going to be predicted using MPS and will be compensated by adjusting the mold surfaces to the as-built geometry rather than the as-designed geometry it might be possible to change the mold material from invar to steel. This would not only reduce the tooling costs but could also further improve the heat-up. 
Since a PID simulation is rather expensive and time consuming, it should be examined beforehand, whether a change in tooling material could yield a significantly improved thermal behavior.
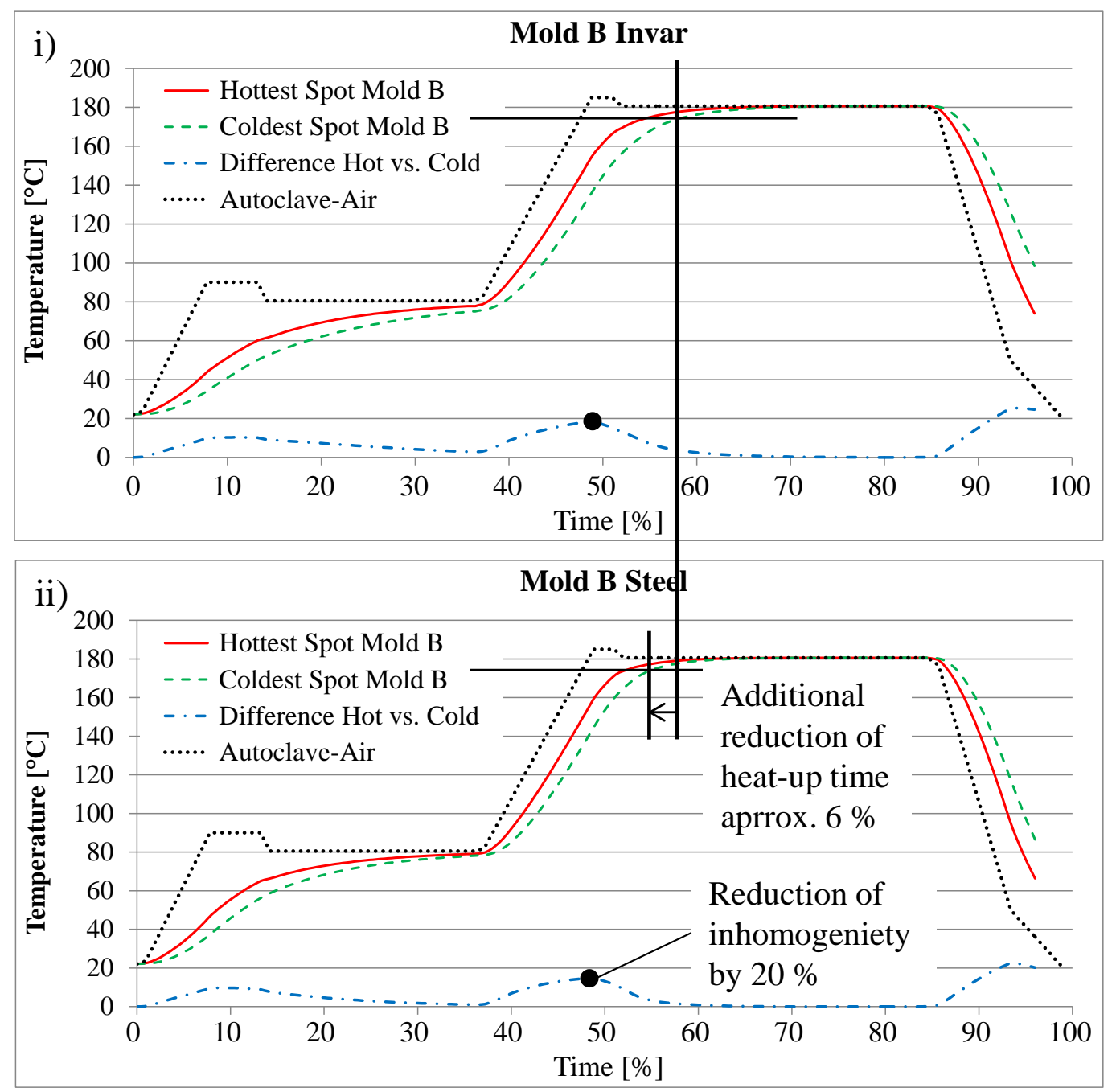

Figure 19. Comparison of mold B made of invar (i) and steel (ii)

Figure 19 reveals that a steel mold will further reduce heat-up times (reduced heat-up to $175^{\circ} \mathrm{C}$ by approx. $6 \%$ ) and improve the temperature homogeneity (reduced temperature difference between hot and cold spot by $4^{\circ} \mathrm{C}$ ). The combination of thermal optimization and PID prediction with MPS will therefore yield a total reduction of $15 \%$ in manufacturing times and an improvement of temperature homogeneity by $66 \%$ (from $44^{\circ} \mathrm{C}$ to $15^{\circ} \mathrm{C}$ ) comparing the original mold A (invar) to the fully improved mold B (steel). 
The case study presented here provides evidence of the great advantages of applying MPS on an industrial scale. MPS allows decision making based on quantitative data rather than experience. Tooling optimization within the virtual design phase of the mold is enabled and even the optimal position or orientation within the autoclave can be determined without a lengthy experimental study.

\section{Summary and Conclusion}

In summary, this paper provides an overview of sheet metal forming simulation and autoclave manufacturing simulation for composite parts. The basic simulation knowledge including model set-up and material characteristics as well as boundary condition requirements are briefly explained and summarized. The Stateof-the-Art section not only explains the simulations and the physical phenomena involved but also presents the information generated for tooling and process optimization as well as the benefits arising from their application.

The second part of the paper explains methods to enable an application of the complex simulation processes on an industrial scale. In the area of metal forming post-processing is optimized by the introduction of a newly developed softwaretool for fast and automated comparison of different simulation results with each other or experiments. The composite manufacturing simulation is optimized by means of automated pre-processing and simplified meshing. Finally, two case studies provide relevant examples for the application of MPS on an industrial scale.

The case study on the sheet metal forming simulation shows how a feasibility study is performed to assess the producibility of a complex part. The case study for the autoclave manufacturing of composite parts demonstrates tooling concept selection and optimization within the virtual design phase with the goal of reducing expensive trial-and-error experiments to almost zero.

The simulation overview, the improvements presented, and especially the case studies provide significant knowledge on how MPS can support manufacturing process development and tooling design. Enabling the prediction of manufacturing outcome and quality within the virtual design phase of the product development process is the main and major benefit of MPS. It supports the improvement of part design, manufacturing processes as well as tooling design while at the same time significantly reducing NRC by avoiding costly experimental studies and time consuming tooling re-work. The authors of this paper highly recommend the use of MPS within the product development process. 


\section{References}

Abdelal, G. F., Robotham, A., \& Cantwell, W. (2013): Autoclave cure simulation of composite structures applying implicit and explicit FE techniques. $I$ ternational Journal of Mechanics and Materials in Design, 9, 55-63. doi: 10.1007/s10999-012-9205-7

Altan, T.; Tekkaya, E. (2012). Sheet metal forming: Processes and Applications. Materials Park, OH: ASM International.

Atzema, E., Abspoel, M., Kömmelt, P., \& Lambriks, M. (2009). Towards robust simulations in sheet metal forming. International Journal of Material Forming. doi: 10.1007/s12289-009-0534-5

Baiker, M., \& Helm, D. (2012). Investigation and modelling of the material behaviour of DC04 steel. Proceedings of the Summer School 2011, Graduate School 1483, Process Chains in Production: Interaction, Modelling and Assessment of Process Zones, pp.17-20

Banabic, D., Comsa, D.S., Sester, M., Selig, M., Kubli, W., Mattiasson, K., \& Sigvant, M. (2008). Influence of constitutive equations on the accuracy of prediction in sheet metal forming simulation. Paper presented at Numisheet 2008, Interlaken, Switzerland

Brauner, C. (2013). Analysis of process-induced distortions and residual stresses of composite structures. (Doctoral dissertation, Logos Verlag, Berlin, Germany)

Cao, J. and Boyce, M. (1993). Draw bead penetration as a control element of material flow. SAE Technical Paper 930517. doi: 10.4271/930517

Dave, R., Kardos, J. L., \& Dudukovic, M. P. (1987). A model for resin flow during composite processing: Part 1 - General mathematical development. Polymer Composites, 8(1), 29-38 doi: 10.1177/002199839302701704

Dodwell, T. J., Butler, R., \& Hunt, G. W. (2014). Out-of-plane ply wrinkling defects during consolidation over an external radius. Composites Science and Technology, 105, 151-159. doi: 10.1016/j.compscitech.2014.10.007 
Duhovic, M., Schommer, D., Hausmann, J., Romanenko, V., \& Weber, T.A. (2017). Simulating the Processing and Fabrication of Advanced materials. Paper presented at the Processing and Fabrication of Advanced Materials XXV, Auckland, NZ.

Elkington, M., Bloom, D., Ward, C., Chatzimichali, A., \& Potter, K. (2015). Hand layup: Understanding the manual process. Advanced Manufacturing: Po ymer \& Composite Science, 1, 128-141. doi: $10.1080 / 20550340.2015 .1114801$

Ghouati, O., \& Chen, X. (2006): Sheet metal forming simulation-Closing the sign loop 5. Paper presented at the LS-DYNA Userforum, Ulm, Germany

Gutowski, T., Cai, Z., Bauer, S., Boucher, D., Kingery, J., \& Wineman, S. (1987). Consolidation Experiments for Laminate Composites. Journal of Composite Materials, 21(7), 650-66.

Hubert, P (1996). Aspects of Flow and Compaction of Laminated Composite Shapes During Cure. (Doctoral dissertation, Vancouver, University of British Columbia, Canada).

Hubert, P., \& Poursartip, A. (1998). A review of flow and compaction modeling relevant to thermoset matrix laminate processing. Journal of Reforced Plastics and Composites, 17(4), 286-318. doi: 10.1177/073168449801700402

Jaina, M., Allina, J., \& Bullb, M. J. (1998). Deep drawing characteristics of automotive aluminum alloys. Materials Science and Engineering: A, 256(12), 69-82. doi: 10.1016/S0921-5093(98)00845-4

Johnston, A. A. (1997). An integrated model of the development of processinduced deformations in autoclave processing of composite structures. (Doctoral dissertation, University of British Columbia, Canada).

Kleiner, M., Geiger, M., \& Klaus, A. (2003). Manufacturing of lightweight components. Metal Forming In CIRP Annals, 52(2), 521-542. doi: 10.1016/S0007-8506(07)60202-91

Kobayashi, S., Oh, S., Altan, T. (1989). Metal forming and the finite-element method. New York: Oxford University Press. 
Livermore Software Technology Corporation (LSTC) (2012). LS-DYNA

Keyword user's manual Volume II Material Models, Version 971, R6.1.0.

Retrieved from http://ftp.lstc.com/anonymous/outgoing/jday/manuals/LSDYNA_manual_Vol_II_R6.1.0.pdf

Lukaszewicz, D. H.-J.A., Ward, C., \& Potter, K. D. (2012). The engineering aspects of automated prepreg layup: History, present and future. Comp sites: Part B, 43, 997-1009. doi: 10.1016/j.compositesb.2011.12.003

Maker, B. N., \& Zhu, X. (2000). Input parameters for metal forming simulation using LS-DYNA. Livermore Software Technology Corporation. Retrieved from http://www.dynalook.com/international-conf-2000/session12-1.pdf

Maker, B. N., \& Zhu, X. (2001). Input parameters for Springback Simulation u ing LS-DYNA. Livermore Software Technology Corporation. Retrieved from http://www.dynalook.com/Personally/springback_maker_zhu.pdf

Makinouchi, A. (1996). Sheet metal forming simulation in industry. Journal of Materials Processing Technology, 60, 19-26. doi: doi.org/10.1016/0924-0136(96)02303-5

Najafi, A., Rais-Rohani, M., \& Hammi, Y (2011). Multi-attribute integrated forming-crush simulation optimization using internal state variable model. Paper presented at the 1st World Congress on Integrated Computational Materials Engineering (ICME). doi: 10.1002/9781118147726.ch6

Osborne, T. (2015). Airbus removes veil from H160 project. Aviation week. Retrieved from http://aviationweek.com/business-aviation/airbus-removesveil-h160-project?eid=forward

Özsoy, Ö., Ersoy, N., \& Wisnom, M. R. (2007): Numerical investigation of toolpart-interactions in composites manufacturing. Paper presented at the 16 th International Conference on Composite Materials ICCM 16. Kyoto, Japan

Raju, S., Ganesan, G., \& Karthikeyan, R. (2010). Influence of variables in deep drawing of AA 6061 sheet. Transactions of Nonferrous Metals Society of China, 20(10), 1856-1862, doi: 10.1016/S1003-6326(09)60386-1

Sikorsky (2016). CH-53K Helicopter: The world's premier heavy lift helicopter is in development at Sikorsky. Retrieved from http://www.sikorsky.com/Pages/Products/Military/CH53/CH53K.aspx 
Strano, M., \& Colosimob, B. M. (2006). Logistic regression analysis for experimental determination of forming limit diagrams. International Jour nal of Machine Tools and Manufacture, 46(6), 673-682. doi: 10.1016/j.ijmachtools.2005.07.005

Tekkaya, A. E. (2000). State-of-the-art of simulation of sheet metal forming. Journal of Materials Processing Technology, 103(1), 14-22, doi: 10.1016/S0924-0136(00)00413-1

Weber, T. A., Arent, J-C., Münch, L., Duhovic, M., \& Balvers, J. M. (2016a) A fast method for the generation of boundary conditions for thermal au toclave simulation. Composite Part A, 88(2016), 216-225. doi: 10.1016/j.compositesa.2016.05.036

Weber, T. A., Arent, J-C., Steffens, L., Balvers, J. M., \& Duhovic, M. (2016b). Thermal optimization of composite autoclave molds using the shift factor approach for boundary condition estimation. Journal of Composite Mate rials, 51(12), 1753-1767. doi: 10.1177/0021998317699868.

Weber, T. \& Balvers, J. M. (2015). Manufacturing process simulation for tooling optimization: Reduction of quality issues during autoclave manufacturing of composite parts. Paper presented at the SAMPE Europe Conference, Amiens, France, 2015.

Weber, T. A., Tellis, J. J., \& Duhovic, M. (2016c). Characterization of tool-partinteraction and interlaminar friction for manufacturing process simulation. Paper presented at the 17th European Congress on Composite Materials, Munich.

Yao, H., Liu, S., Du, C., \& Hu, Y. (2002). Techniques to improve Springback prediction accuracy using dynamic explicit FEA Codes. SAE Technical Paper 2002-01-0159, doi: 10.4271/2002-01-0159.

Younossi, O., Kennedy, M. \& Graser, J. C. (2001). Military airframe costs: The effects of advanced materials and manufacturing processes. Santa Monica, CA: RAND Corporation 
Xie, G.; Lui, J., Zhang, W., \& Sunden, B. (2012). Simulation and Thermal Analy sis on temperature fields during composite curing process in autoclave technology. Paper presented at ASME 2012 International Mechanical Engineering Congress and Exposition, Vol. 7, Houston, TX, 2012, pp. 1-9. 